Issued by Sandia National Laboratories, operated for the United States Department of Energy by Sandia Corporation.

NOTICE: This report was prepared as an account of work sponsored by an agency of the United States Government. Neither the United States Government, nor any agency thereof, nor any of their employees, nor any of their contractors, subcontractors, or their employees, make any warranty, express or implied, or assume any legal liability or responsibility for the accuracy, completeness, or usefulness of any information, apparatus, product, or process disclosed, or represent that its use would not infringe privately owned rights. Reference herein to any specific commercial product, process, or service by trade name, trademark, manufacturer, or otherwise, does not necessarily constitute or imply its endorsement, recommendation, or favoring by the United States Government, any agency thereof, or any of their contractors or subcontractors. The views and opinions expressed herein do not necessarily state or reflect those of the United States Government, any agency thereof, or any of their contractors.

Printed in the United States of America. This report has been reproduced directly from the best available copy.

Available to DOE and DOE contractors from

U.S. Department of Energy

Office of Scientific and Technical Information

P.O. Box 62

Oak Ridge, TN 37831

Telephone: (865)576-8401

Facsimile: (865)576-5728

E-Mail: reports@adonis.osti.gov

Online ordering: http://www.doe.gov/bridge

Available to the public from

U.S. Department of Commerce

National Technical Information Service

5285 Port Royal Rd

Springfield, VA 22161

Telephone: (800)553-6847

Facsimile: (703)605-6900

E-Mail: orders@ntis.fedworld.gov

Online order: http://www.ntis.gov/ordering.htm

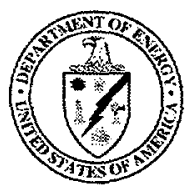




\section{DISCLAIMER}

Portions of this document may be illegible in electronic image products. Images are produced from the best available original document. 
SAND2000-1111

Unlimited Release

Printed May 2000

\title{
Sandia Heat Flux Gauge Thermal Response and Uncertainty Models
}

\author{
T. K. Blanchat and L. L. Humphries \\ Nuclear Safety Testing Department \\ W. Gill \\ Reactive Processes Department \\ Sandia National Laboratories \\ P.O. Box 5800 \\ Albuquerque, NM 87185-1139
}

\begin{abstract}
The Sandia Heat Flux Gauge (HFG) was developed as a rugged, cost-effective technique for performing steady state heat flux measurements in the pool fire environment. The technique involves reducing the time-temperature history of a thin metal plate to an incident heat flux via a dynamic thermal model, even though the gauge is intended for use at steady state. In this report, the construction of the gauge is reviewed. The thermal model that describes the dynamic response of the gauge to the fire environment is then advanced and it is shown how the heat flux is determined from the temperature readings. This response model is based on first principles, with no empirically adjusted constants. A validation experiment is presented where the gauge was exposed to a step input of radiant heat flux. Comparison of the incident flux, determined from the thermal response model, with the known flux input shows that the gauge exhibits an noticeable time lag. The uncertainty of the measurement is analyzed, and an uncertainty model is put forth using the data obtained from the experiment. The uncertainty model contains contributions from seventeen separate sources loosely categorized as being either from uncontrolled variability, missing physics, or simplifying assumptions. As part of the missing physics, an empirical constant is found that compensates for the gauge time lag. Because this compensation is incorporated into the uncertainty model instead of the response model, this information can be used to advantage in analyzing pool fire data by causing large uncertainties in non-steady state situations. A short general discussion on the uncertainty of the instrument is presented along with some suggested design changes that would facilitate the determination and reduction of the measurement uncertainty.
\end{abstract}


This page intentionally left blank 


\section{CONTENTS}

\section{Page}

INTRODUCTION

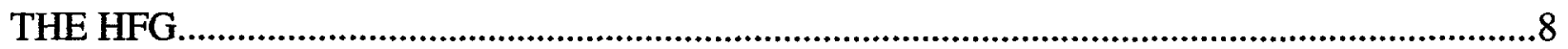

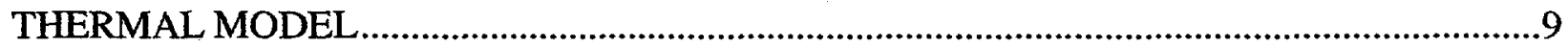

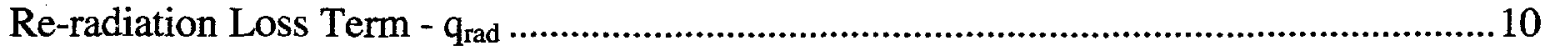

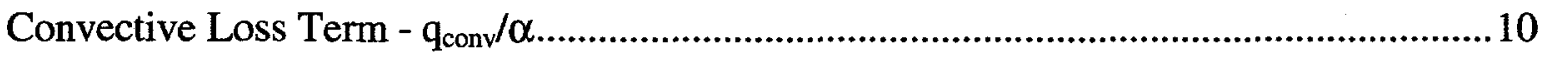

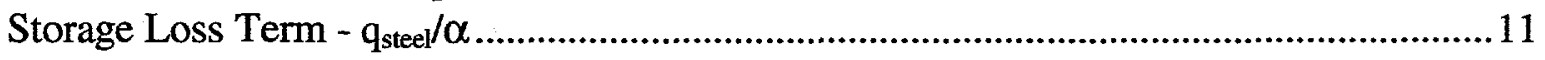

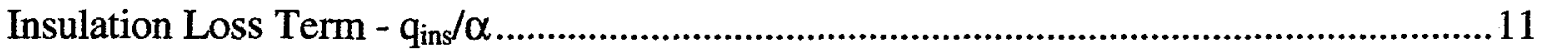

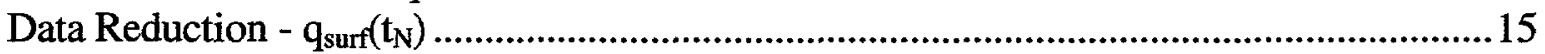

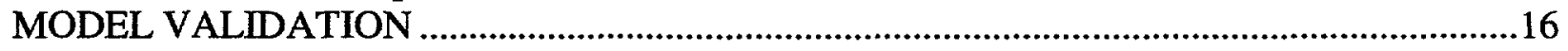

Experimental Setup and Operation........................................................................................16

Correction for Convective Heat Transfer .............................................................................17

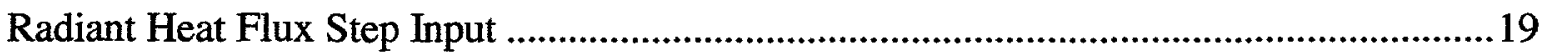

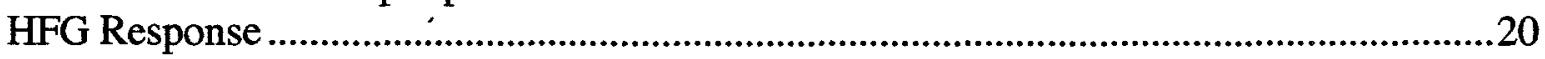

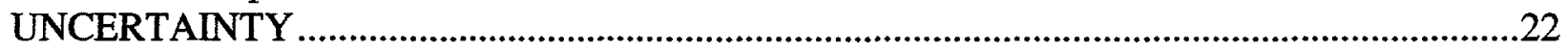

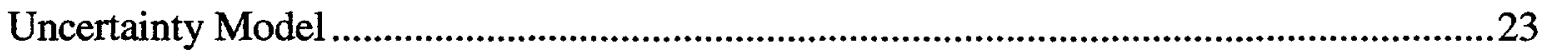

Uncontrolled Variability ......................................................................................................23

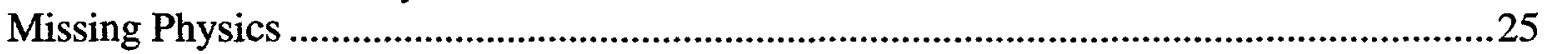

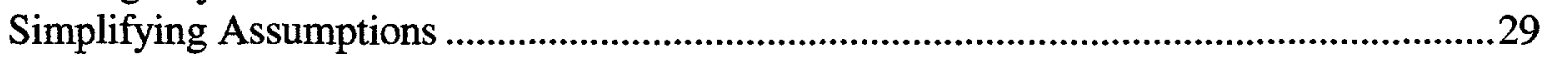

Application to Validation Experiment .....................................................................................31

Effect of Sampling Frequency on Calculated Error ………...................................................33

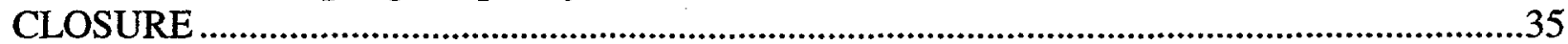

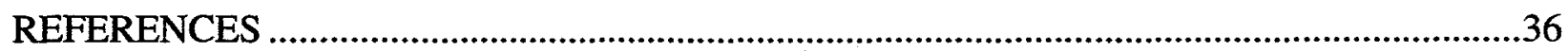

APPENDIX A SNL Hemispherical Heat Flux Gauge Assembly and Construction Details.........37 


\section{FIGURES}

$\underline{\text { Page }}$

Figure 1. Example of a measurement and associated uncertainty using the HFG in a pool fire. Note the uncertainty limits may not always contain the measurement................7

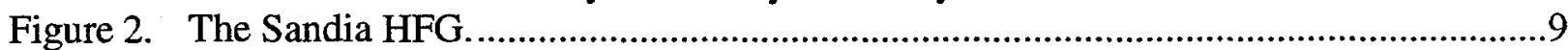

Figure 3. The 1-D thermal model of the HFG. ............................................................. 10

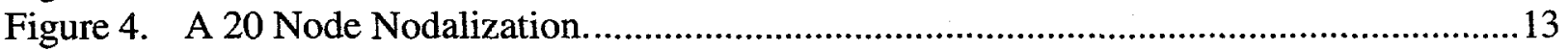

Figure 5. Thermal conductivity of Kaowool ${ }^{\circledR}$ at various blanket densities.............................14

Figure 6. Specific heat of Kaolin............................................................................. 14

Figure 7. Experiment setup for realizing a step increase of radiant heat flux to the HFG. ......16

Figure 8. Operation of the experimental setup showing the heat up of the cavity and the step input of heat flux as recorded by the Gardon gauge. ........................................ 17

Figure 9. An assumed convection cell in the test cavity results in convective heat transfer from the air to the gauges located in the mouth of the cavity. ............................... 18

Figure 10. Estimated convective heat transfer coefficient for a surface facing up into the cavity as a function of surface temperature (air temperature $=1000^{\circ} \mathrm{C}$ ) $\ldots \ldots \ldots \ldots \ldots \ldots . . . . .18$

Figure 11. Step input of radiant heat flux to the HFG. ......................................................19

Figure 12. Measured versus calculated incident heat flux.............................................20

Figure 13. Calculated temperature profile in Kaowool ${ }^{\circledR}$ insulation. ........................................21

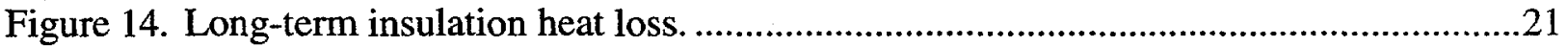

Figure 15. Estimate of the uncertainty of measurement of the step input. .............................22

Figure 16. The thermocouple lags the actual plate temperature. The lag can be corrected with a first order model. .................................................................................26

Figure 17. Experimental determination of the time constant for the first order correction to

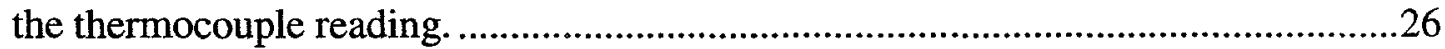

Figure 18. The normal emittance of Pyromark as a function of source temperature [6]............30

Figure 19. Relative importance of the different sources of uncertainty during a step input of $100 \mathrm{~kW} / \mathrm{m}^{2}$

Figure 20. Heat flux calculated for various sampling frequencies. ........................................33

Figure 21. Heat flux error range calculated for various sampling frequencies..........................34

\section{TABLES}

Table 1. Uncontrolled Variability as Uncertainty Sources............................................24

Table 2. Uncontrolled Variability as Uncertainty Sources from the Systematic Error

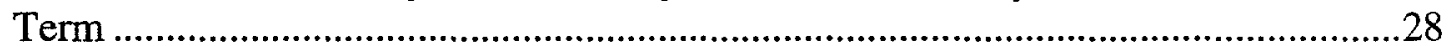

Table 3. Simplifying Assumptions as Uncertainty Sources ...........................................31 


\section{INTRODUCTION}

Over the past several years, hydrocarbon fueled pool fire experiments have been performed both at Sandia National Laboratories' (SNL) Lurance Canyon Burn Facility and the Navy's China Lake Large Scale Pool Fire Facility where measurements of radiative heat fluxes were made using the Sandia Heat Flux Gauge (HFG). HFGs were developed by SNL as a rugged, costeffective technique for performing heat flux measurements in the pool fire environment. The technique involves reducing the time-temperature history of a fire exposed surface as measured by a thermocouple, to a time resolved heat flux via a thermal model that is valid during times of steady-state within the fire environment. Three issues have arisen with respect to the technique. First, the original thermal model which incorporates empirically derived time constants did not perform well in a recent calibration experiment. Second, the original thermal model is not amenable to the formulation of an uncertainty statement that should accompany heat flux measurements in application. And third, it is not always clear from the data as to when steadystate is achieved and the measurement is valid. To address these issues, we herein put forth an alternative thermal model that avoids the use of time constants by allocating, in part, their effect to the uncertainty of the measurement. The uncertainty becomes coupled to the dynamic behavior of the gauge with large values of uncertainty signaling when the gauge is not in equilibrium with the fire environment. We believe this approach results in an improved data reduction technique that is of use in reducing the data collected from previous fires.

Figure 1 shows a typical time-temperature history from an HFG reduced to the incident heat flux. Also in the figure, the uncertainty of the measurement is shown as error bars for each data point.

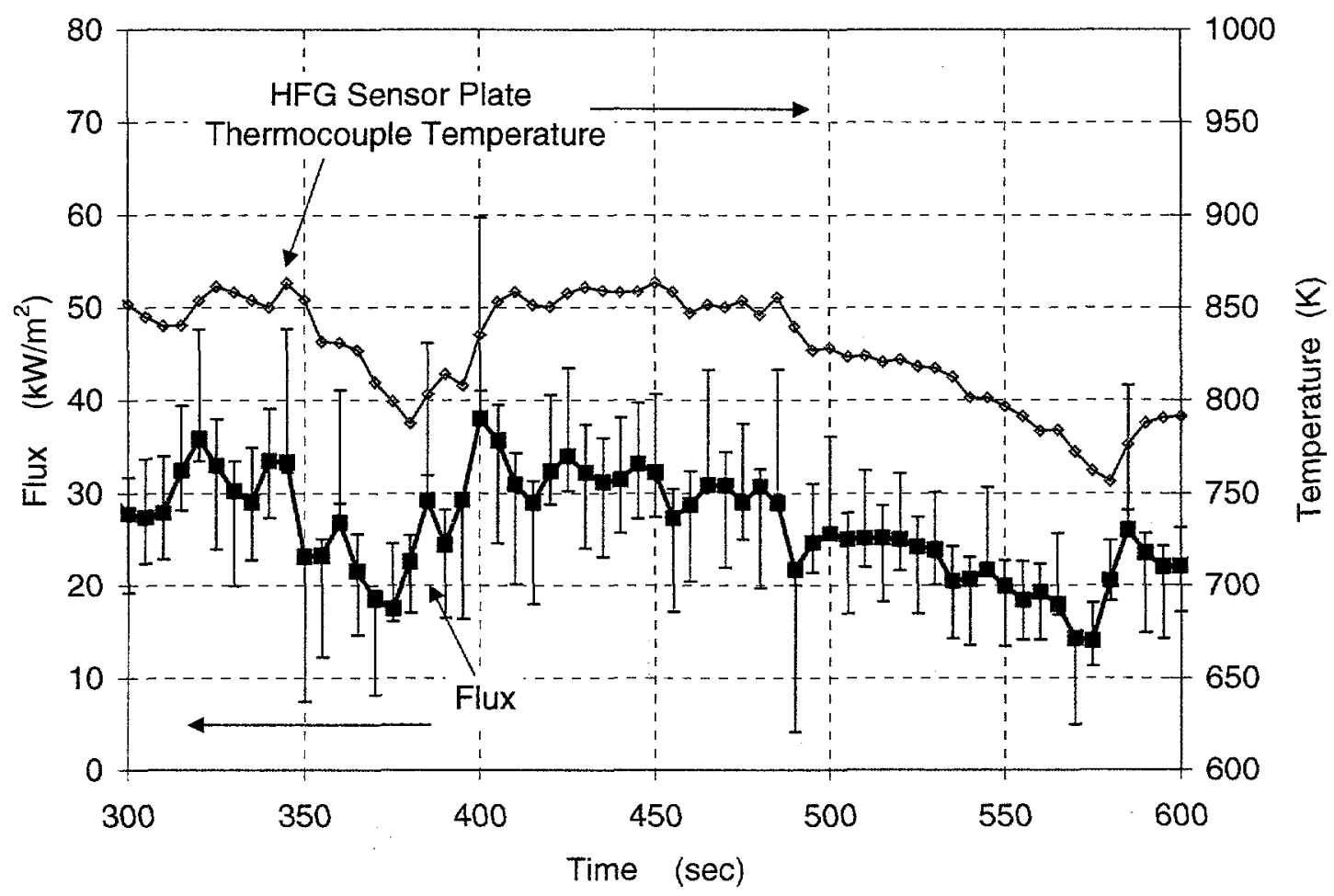

Figure 1. Example of a measurement and associated uncertainty using the HFG in a pool fire. Note the uncertainty limits may not always contain the measurement. 
The heat flux was determined by applying the proposed thermal model, and the uncertainty was found from the accompanying uncertainty model. It is worth noting the uncertainty is large during times of dynamic change and can be used to assess the existence of steady state. The thermal model is based on first principles, with no empirically adjusted constants. The uncertainty model contains contributions from seventeen separate sources loosely categorized as being either from uncontrolled variability, missing physics, and simplifying assumptions. The uncontrolled variability and simplifying assumptions are the major contributors to the uncertainty during times of steady-state operation, and the missing physics are responsible for the large increase in uncertainty during dynamic changes.

In what follows, the gauge construction is first reviewed. It will be seen that the gauge is essentially a thin metal plate that responds to heating from the fire environment. A thermal model that describes the response is then advanced and it is shown how to determine the heat flux from the fire environment via the time-temperature history of the thin metal plate. A validation experiment is presented where the gauge was exposed to a step input of radiant heat flux. Comparison of the incident flux determined from the thermal model with the known flux input shows that the gauge exhibits a noticeable time lag. The uncertainty of the measurement is analyzed, and an uncertainty model is put forth using the data obtained from the experiment. An empirical constant is found that compensates for the gauge time lag. This compensation is incorporated into the uncertainty model instead of the response model, and it is shown how this information can be used to advantage in analyzing pool fire data. Finally, a short general discussion on the uncertainty of the instrument is presented along with some suggested design changes to the HFG that would facilitate the determination and reduction of the measurement uncertainty associated with the HFG.

\section{THE HFG}

The HFG is intended to function by exposing one side of a thin metal plate to the fire environment and observing the temperature response. Ideally, the plate is perfectly isolated, i.e., the unexposed side and the edges of the plate are thermally insulated. Furthermore, if the plate is assumed to be thermally thin, gradients through the plate and along the lateral direction can be ignored. These assumptions allow interpreting the temperature measured at a single point on the unexposed surface as the one-dimensional response of a heated composite wall.

To meet the requirements of a one-dimensional response, the gauge shown in Figure 2 was developed. The assembly is essentially a hollow cylinder filled with thermal insulation that is fitted with sensor plates on each end. The body of the HFG is a $10-\mathrm{cm}$ long cylinder of $10.2-\mathrm{cm}$ diameter schedule 40 steel pipe. The body is filled with Cerablanket ${ }^{\circledR}$ ceramic fiber insulation to minimize heat transfer inside the HFG. The entire assembly is held together with four $14-\mathrm{cm}$ stainless steel bolts. See Appendix A for construction drawings and fabrication details.

The sensor plates are $10.2-\mathrm{cm}$ squares of $0.025-\mathrm{cm}$ thick 304 stainless steel shim-stock. The plates are held in place on the cylindrical body by endplates that are $10.2-\mathrm{cm}$ square by $0.32-\mathrm{cm}$ thick 304 stainless steel with a centered $5.0-\mathrm{cm}$ hole. The sensor surfaces are thermally isolated 


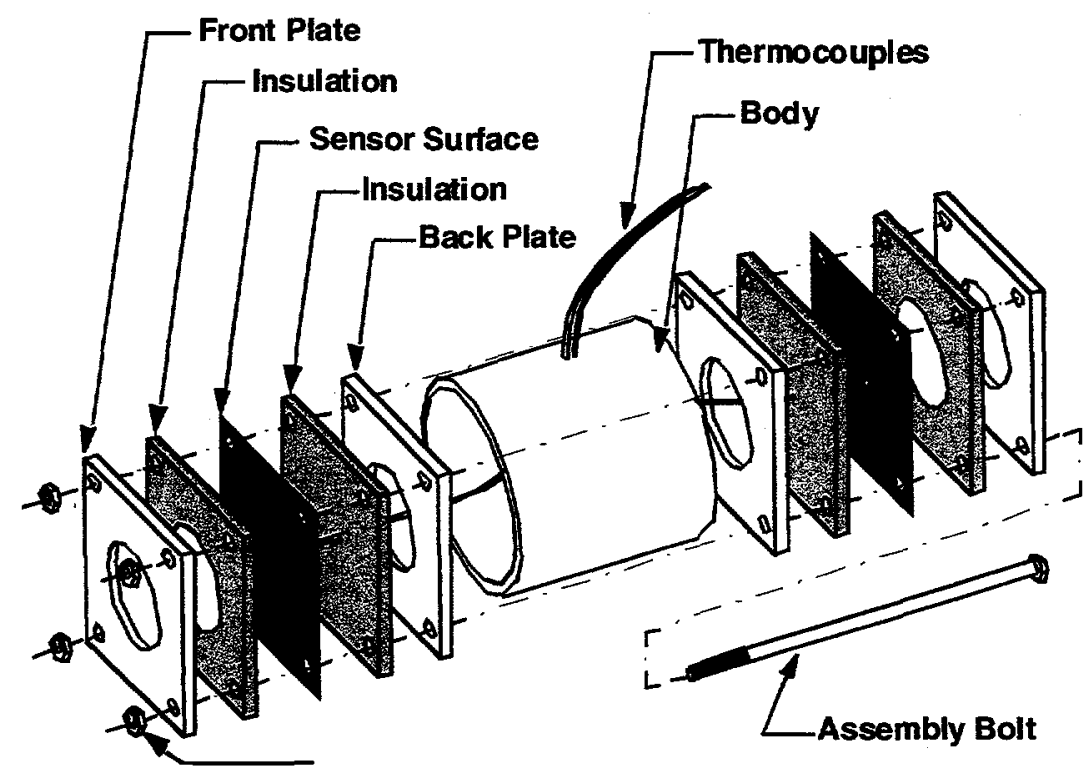

Figure 2. The Sandia HFG.

from the remainder of the HFG by two layers of Lytherm ${ }^{\circledR}$ ceramic fiber insulation. The front sides of the sensor surfaces are coated with Pyromark ${ }^{\circledR}$ paint to achieve a diffuse gray surface. A 0.16-cm diameter Inconel-sheathed type-K thermocouple is used as the sensor thermocouple. The sensor thermocouple is attached to the sensor surface with $0.01-\mathrm{cm}$ thick retainer straps that are spot-welded to the back of the sensor surface.

For most of the data taken to date, the gauge has been constructed with only one sensor plate. Only one end was exposed to the fire, and the sensor plate on the other end was replaced with a flat plate (304 stainless steel, $10.2-\mathrm{cm}$ square, $0.32-\mathrm{cm}$ thick).

\section{THERMAL MODEL}

The heat balance on the heated surface of an idealized one-dimensional heat flux gauge (Figure 3) can be summarized in the following equation,

$$
\alpha q_{\text {surf }}(t)=\varepsilon \cdot q_{\text {rad }}(t)+q_{\text {conv }}(t)+q_{\text {steel }}(t)+q_{\text {insul }}(t)
$$

where $q_{\text {sur }}(t)$ is the heat flux incident to the heated surface, $q_{\mathrm{rad}}(t)$ represents the heat re-radiated from the sensor surface, $q_{\text {conv }}(t)$ is the convective heat loss at the sensor surface, $q_{\text {steel }}(t)$ is the sensible heat stored in the thin 304 stainless steel sensor plate, and $q_{\text {insul }}(t)$ represents the heat conducted into the insulated backing. Absorptivity and emissivity of the steel surface are represented by $\alpha$ and $\varepsilon$, respectively. 


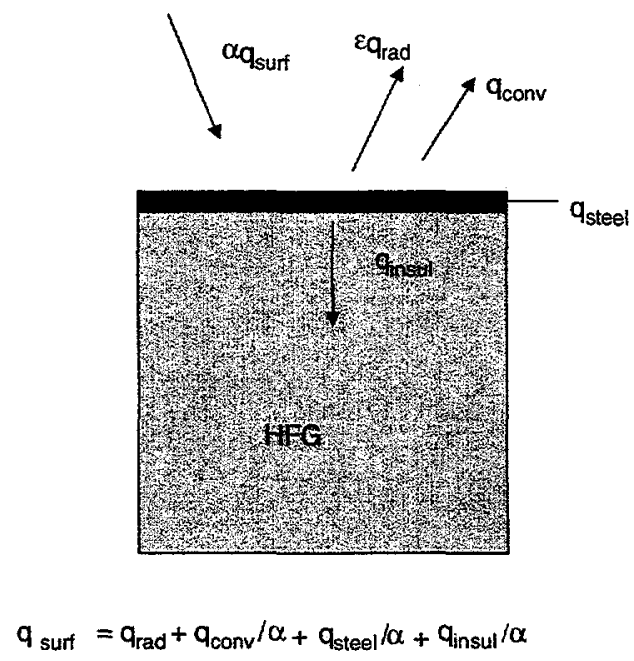

Figure 3. The 1-D thermal model of the HFG.

To implement this model in a data reduction scheme, each one of the loss terms is related to the instantaneous temperature of the sensor plate. Since the data is normally acquired digitally, and temperatures other than the observed sensor plate have to be considered, the following nomenclature is adopted. $T_{i}^{N}$ is the temperature at the end of the $N^{\text {th }}$ time step (corresponding to the time $t_{N}$ ) at the $i^{\text {th }}$ location. The sensor plate corresponds to $i=1$, and increasing values of $i$ are in-depth positions within the thermal insulation. Thus, $T_{1}^{N}$ is the observed temperature of the sensor plate at time step $N$. In what follows, the loss terms are calculated in terms of $T_{1}^{N}$ and added to provide a "reading" of the heat flux, $q\left(t_{N}\right)$, on the surface from the fire environment.

\section{Re-radiation Loss Term - $q_{r a d}$}

The re-radiation term is based on the Stefan-Boltzmann law

$$
q_{r a d}\left(t_{N}\right)=\sigma \cdot\left(T_{1}^{N}\right)^{4}
$$

with $\sigma=5.67 \times 10^{-11} \mathrm{~kW} / \mathrm{m}^{2} \mathrm{~K}^{4}$.

\section{Convective Loss Term - $q_{\text {conv }} / \alpha$}

The convection term is modeled as

$$
\frac{q_{c o n v}\left(t_{N}\right)}{\alpha}=\frac{h\left(T_{1}^{N}-T_{\text {amb }}\right)}{\alpha}
$$

where the heat transfer coefficient $h$ must be determined from knowledge of the gauge installation, the temperature of the ambient fluid in contact with the sensor face $T_{a m b}$, and flow conditions over the surface. 


\section{Storage Loss Term $-q_{\text {steed }} / \alpha$}

The heat flux absorbed into the thin steel sensor plate is calculated using the surface plate thermocouple temperature derivative using a central difference, i.e.,

$$
\frac{q_{\text {stel }}\left(t_{N}\right)}{\alpha}=\frac{\rho \cdot C_{p}\left(T_{1}^{N}\right) \cdot L}{\alpha} \frac{d T_{1}^{N}}{d t} \approx \frac{\rho \cdot C_{p}\left(T_{I}^{N}\right) \cdot L}{\alpha} \cdot \frac{\left(-T_{1}^{N+2}+8 \cdot T_{1}^{N+1}-8 \cdot T_{I}^{N-1}+T_{I}^{N-2}\right)}{12 \cdot\left(t_{N+1}-t_{N}\right)}
$$

The 304 stainless steel sensor plate density and specific heat properties are temperature dependent and can be calculated using the following equation (temperature in $\mathrm{K}$ ) [1].

$$
\begin{aligned}
\rho \cdot C_{p}(T)= & 1215.769+14.969 \cdot T-0.029 \cdot T^{2}-2.991 \mathrm{e}-5 \cdot T^{3}-1.472 \mathrm{e}-8 \cdot T^{4} \\
& +2.818 \mathrm{e}-12 \cdot T^{5} \quad\left[\mathrm{~kJ} / \mathrm{m}^{3} / \mathrm{K}\right]
\end{aligned}
$$

$\mathrm{L}$, the thin steel HFG sensor plate thickness is $0.0254 \mathrm{~cm}$.

\section{Insulation Loss Term - $q_{\text {ins }} / \alpha$}

The relation between the sensor plate temperature and the heat loss into the insulation is obtained by considering the response of the surface of a thick wall subject to a time varying temperature on one surface and perfect insulation on the other surface. An algorithm for calculating the heat flux into the insulated backing given the thermocouple response at the surface has been derived by numerically modeling the transient thermal response of the insulating material. The onedimensional heat conduction equation with no internal heat generation and temperature dependent properties is written as:

$$
\rho c_{p} \frac{\partial T(z, t)}{\partial t}=\frac{\partial}{\partial z} k \frac{\partial T(z, t)}{\partial z}
$$

where $k, \rho$, and $c_{p}$ are functions of the temperature field. This equation can be cast in finite difference form as follows (time is designated as superscript $N$ and location as subscript $i$ ):

$$
\rho_{i} c_{p_{i}} \frac{T_{i}^{N+1}-T_{i}^{N}}{d t}=\frac{k_{i-1 / 2}}{d z_{i-1}} T_{i-1}^{N+1}-\left(\frac{k_{i-1 / 2}}{d z_{i-1}}+\frac{k_{i+1 / 2}}{d z_{i}}\right) T_{i}^{N+1}+\frac{k_{i+1 / 2}}{d z_{i}} T_{i+1}^{N+1}
$$

Note that the conductivity is evaluated at the average mid-point temperature between nodes while density and specific heat are evaluated at the nodal temperature for the preceding time step. This equation is implicit since the heat flux (right hand side of the equation) is evaluated at the advanced time step $N+1$. This equation results in the following linear system of equations. 


$$
\begin{array}{rlr}
c_{1,1} T_{1}+c_{1,2} T_{2} & & =d_{1} \\
c_{2,1} T_{1}+c_{2,2} T_{2}+c_{2,3} T_{3} & & d_{2} \\
c_{3,2} T_{2}+c_{3,3} T_{3}+c_{3,4} T_{4} & & d_{3} \\
c_{i, i-1} T_{i-1}+c_{i, i} T_{i}+c_{i, i+1} T_{i+1} & \\
\ldots & =d_{i} \\
c_{I-1, I-2} T_{I-2}+c_{I-1, I-1} T_{I-1}+c_{I-1, I} T_{I} & =d_{I-1} \\
c_{I, I-1} T_{I-1}+c_{I, I} T_{I} & =d_{I}
\end{array}
$$

In these equations, the coefficients $\mathrm{c}$ are functions of material properties (and time step along the diagonal), the values of $\mathrm{d}$ are functions of material property, time step, and the temperature at the preceding time step, and the vector $\mathrm{T}$ is the temperature field at the end of the time step. This system is a tri-diagonal set of equations, which can be solved by Gaussian elimination. The resulting algorithm can then be summarized with the following set of equations.

$$
\begin{gathered}
T_{I}=\gamma_{I} \\
T_{i}=\gamma_{i}-\frac{c_{i, i+1} T_{i+1}}{\beta_{i}}, \quad i=I-1, I-2, \ldots, 1 \\
\beta_{1}=c_{1,1} \quad \gamma_{1}=d_{1} / \beta_{1} \\
\beta_{i}=c_{i, i}-\frac{c_{i, i-1} c_{i, i+1}}{\beta_{i-1}}, \quad i=2,3, \ldots, I \\
\gamma_{i}=\frac{d_{i}-c_{i, i-1} \gamma_{i-1}}{\beta_{i}}, \quad i=2,3, \ldots, I
\end{gathered}
$$

The nodalization is chosen such that node spacing is much finer near the heated surface than through the bulk of the insulation. This objective is achieved by prescribing a geometrically increasing node spacing, i.e.,

$$
d z_{i}=d z_{i-1} r^{i}
$$

For 20 nodes, and $\mathrm{r}=1.2$, and $7.62 \mathrm{~cm} \mathrm{Kaowool}{ }^{\circledR}$ insulation thickness, the nodalization is shown in Figure 4. 


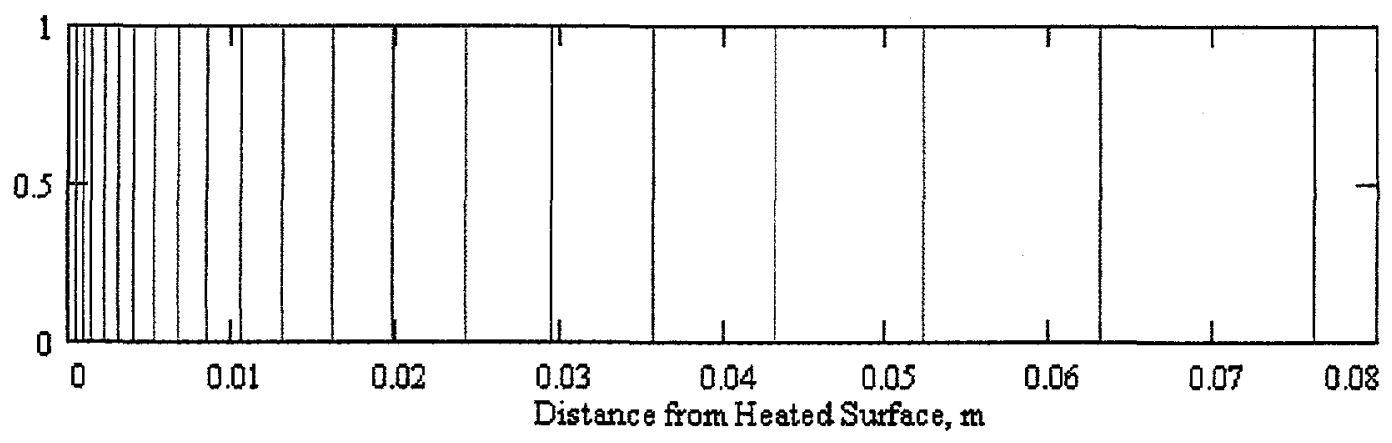

Figure 4. A 20 Node Nodalization.

Note that the number of nodes and the geometric ratio, $\mathrm{r}$, can be varied to optimize the nodalization. When the number of nodes is very large, care should be taken in selecting the ratio $r$, since a large ratio will result in very large nodes through the bulk of the insulation. When $r=$ 1 , the nodalization collapses to the uniform case.

Thermal properties are evaluated from polynomial curve fits to the manufacturer's data. For 128 $\mathrm{kg} / \mathrm{m}^{3}\left(8 \mathrm{lb} / \mathrm{ft}^{3}\right)$ Kaowool ${ }^{\circledR}$ blanket (typically used interchangeably with Cerablanket ${ }^{\circledR}$ in the SNL $\mathrm{HFG}$ ),

$$
\begin{gathered}
k(T)=-6.05 \cdot 10^{-3}+6.98 \cdot 10^{-5} \mathrm{~T}+1.04 \cdot 10^{-7} T^{2} \quad[\mathrm{~kW} / \mathrm{m} / \mathrm{K}] \text { and } \\
\rho c_{p}(T)=128 \cdot(739.72733+.2483608 \mathrm{~T}) \quad\left[\mathrm{J} / \mathrm{m}^{3} / \mathrm{K}\right]
\end{gathered}
$$

as plotted in Figure 5 and Figure 6. Note that Kaolin is the raw, mineral material melted to form the fibers of both the $\mathrm{Kaowool}^{\circledR}$ and $\mathrm{Cerablanket}^{\circledR}$ insulation. Because temperatures at the surface of the heat flux gauge can vary widely in a fire test and thermal properties, such as thermal conductivity in particular, are strongly dependent on temperature, it is important to use temperature-dependent properties in this evaluation.

For data reduction, this algorithm is implemented in a computer subroutine, which calculates the temperature field in the insulation at the end of a time step for a prescribed temperature boundary condition on the heated surface. The instantaneous thermocouple reading is used as the surface boundary condition to the insulation. Since the insulation is assumed to be thick, an adiabatic boundary condition is chosen for the opposite side. For the single sided gauge, this surface is located at a distance equal to the total length of the gauge. For the double sided gauge, this surface is located at a distance equal to half the length of the actual gauge. 


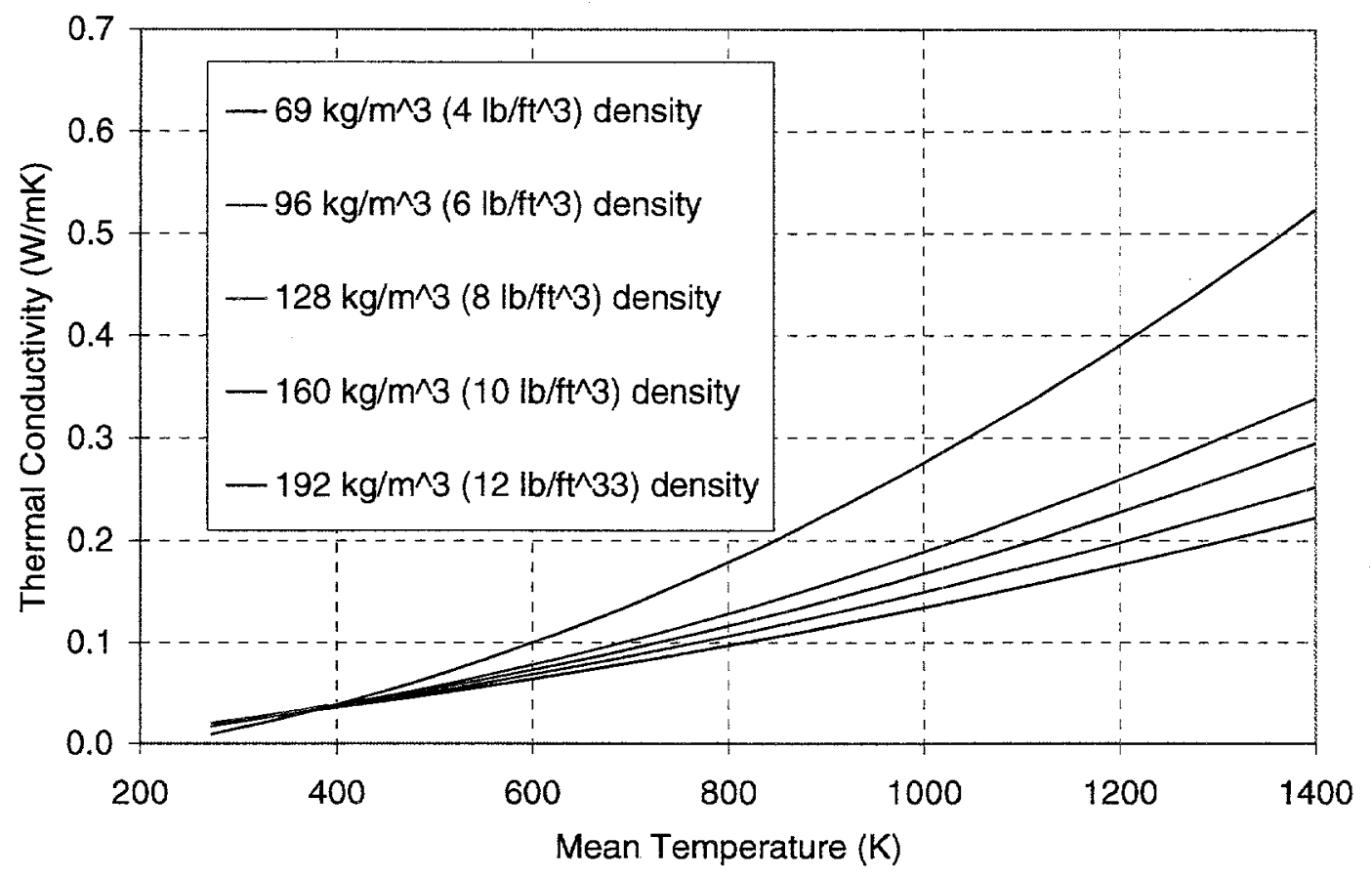

Figure 5. Thermal conductivity of Kaowool ${ }^{\circledast}$ at various blanket densities.

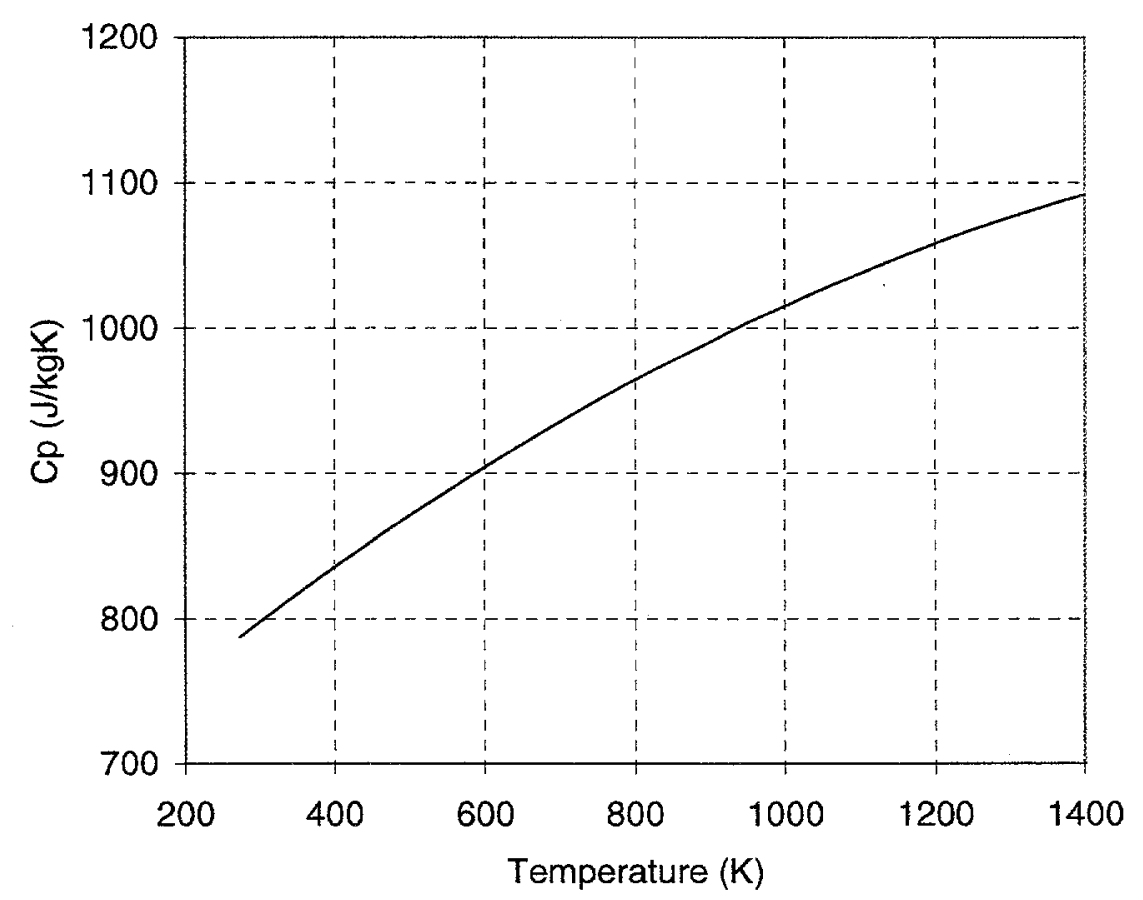

Figure 6. Specific heat of Kaolin. 
The heat flux to the insulation is then calculated from the derived temperature field by taking the derivative of the temperature gradient at the surface, i.e.,

$$
\frac{q_{\text {ins }}\left(t_{N}\right)}{\alpha}=\frac{k\left(T_{1+1 / 2}^{N}\right)}{\alpha} \cdot \frac{\left(T_{1}^{N}-T_{2}^{N}\right)}{d z_{1}} .
$$

\section{Data Reduction - $q_{\text {surf }}\left(t_{N}\right)$}

Summing the losses for any time, $t_{N}$, results in:

$$
\begin{aligned}
q_{\text {surf }}\left(t_{N}\right)= & \sigma \cdot\left(T_{1}^{N}\right)^{4}+\frac{h \cdot\left(T_{1}^{N}-T_{a m b}\right)}{\alpha} \\
& +\frac{\rho \cdot C_{p}\left(T_{1}^{N}\right) \cdot L}{\alpha} \cdot \frac{\left(-T_{1}^{N+2}+8 \cdot T_{1}^{N+1}-8 \cdot T_{1}^{N-1}+T_{1}^{N-2}\right)}{12 \cdot\left(t_{N+1}-t_{N}\right)} \\
& +\frac{k\left(T_{l+1 / 2}^{N}\right)}{\alpha} \cdot \frac{\left(T_{1}^{N}-T_{2}^{N}\right)}{d z_{1}}
\end{aligned}
$$

where $T_{1}^{N}$ is the thermocouple reading in $\mathrm{K}$ at the $N^{\text {th }}$ time step. $T_{1+1 / 2}^{N}$ and $T_{2}^{N}$ are determined by running the thick wall subroutine using $T_{i}^{N-1}$ as the initial values.

Microsoft ${ }^{\circledR}$ Visual Basic macros have been written to perform heat flux gauge analysis for data in MS Excel ${ }^{\circledR}$ spreadsheets. The subroutine $h f l u x$ calculates the various heat flux terms found in the energy balance to arrive at a total incident heat flux. Time and temperature arrays are passed to this subroutine as real arrays in the argument list, and the incident heat flux is returned as a real array. The dimension of the arrays is calculated within hflux and variable array sizes are allowed.

Currently there are certain assumptions or specifications inherent in these macros that may be peculiar to the specific heat flux gauges tested, i.e.,

- The stainless steel sensor plate is $.0254 \mathrm{~cm}$ thick

- The emissivity, $\varepsilon$, of the sensor plate is .85

- $\rho c_{\mathrm{p}}$ for the sensor plate is specified for 304 stainless steel

- Convection is modeled with a specific expression (discussed below) that is not applicable in a general sense

- The insulation is a $7.62 \mathrm{~cm}$ thick Kaowool ${ }^{\oplus}$ blanket.

Heat losses to the insulation are calculated in the subroutine insul as described in the preceding section. Currently the insulation is modeled as $7.62 \mathrm{~cm}$ thick Kaowool ${ }^{\circledR}$ blanket material and transverse heat losses are ignored, i.e., one-dimensional heat transfer. The model has 20 nodes that are geometrically spaced with a ratio of 1.2 . 


\section{MODEL VALIDATION}

\section{Experimental Setup and Operation}

To validate the model, we chose to subject the gauge to a step input of radiant heat flux to a level commensurate with that found in typical fire experimentation. Response to a step input is particularly desirable in that shortcomings in the data reduction technique are revealed, and global characteristics of interest such as instrument order and response time are directly observable.

To accomplish the step input, the HFG was placed below and facing up into a heated cavity whose walls are maintained at a constant temperature (Figure 7). The cavity, $1 \mathrm{~m}$ in diameter by $1.3 \mathrm{~m}$ deep, is formed from a cylindrically-shaped Inconel shroud with heat lamps directed toward the outside of the shroud to control the temperature of the cavity. A cover is placed over the HFG while the cavity is brought to the desired temperature (typically $1000 \mathrm{C}$ ). The step input to the HFG is initiated by removing the cover. A Gardon gauge is positioned next to the HFG to observe the same flux and provide a standard for comparison.

Figure 8 shows the average temperature of the shroud and the response of the Gardon gauge as a function of time. In that figure, heating of the cavity began at about 3 minutes and steady state at $1000^{\circ} \mathrm{C}$ was achieved at about 7 minutes. At that time, the gauges were uncovered resulting in a step change in heat flux from 0 to about $110 \mathrm{~kW} / \mathrm{m}^{2}$. This flux level was held constant for a 30 minute period, at which time the gauges were covered and the power to the heat lamps turned off. Further details on the setup and operation of this system are given in [2].

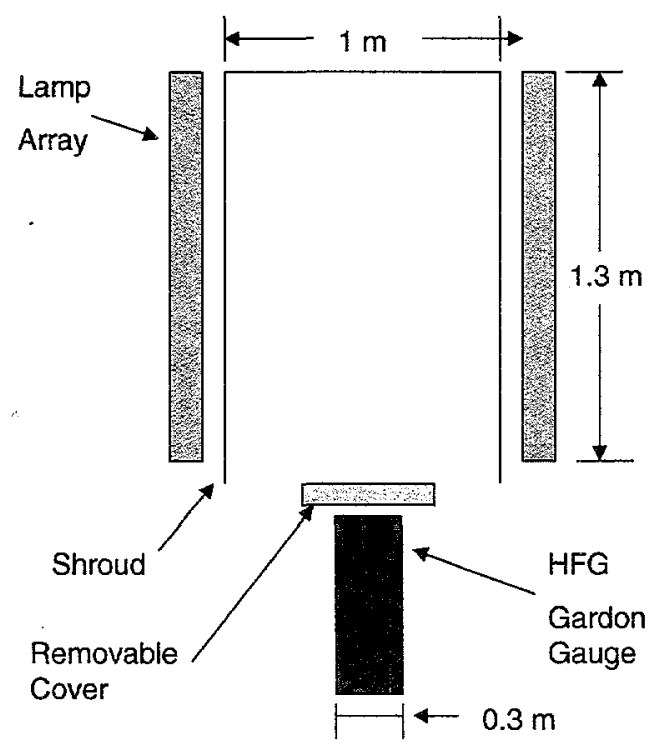

Figure 7. Experiment setup for realizing a step increase of radiant heat flux to the HFG. 


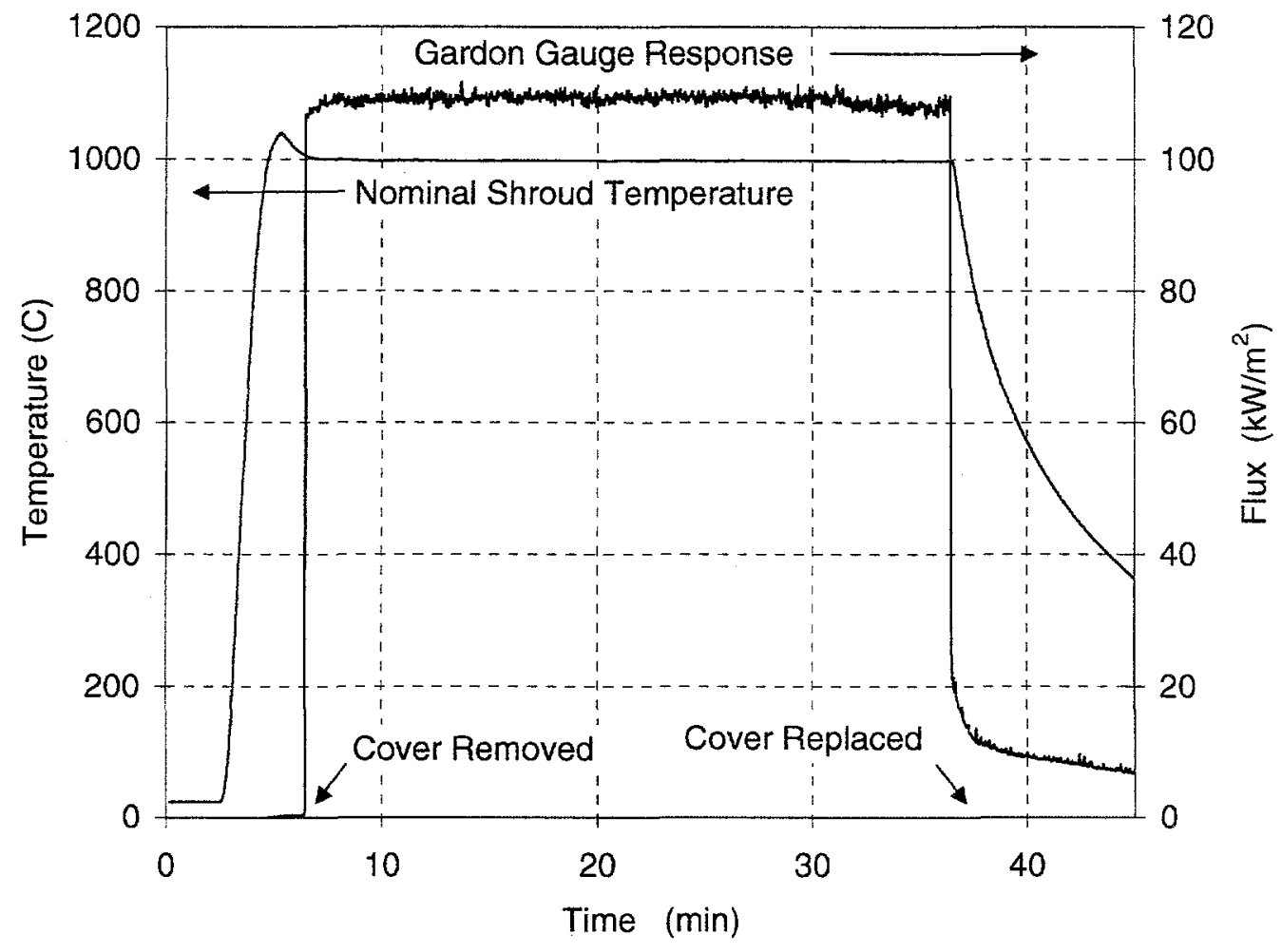

Figure 8. Operation of the experimental setup showing the heat up of the cavity and the step input of heat flux as recorded by the Gardon gauge.

\section{Correction for Convective Heat Transfer}

For comparing the Gardon reading to the HFG response, the convection heat transfer between the ambient air in the cavity and the Gardon gauge must be taken into account. To do this, it is assumed that a convection cell forms in the cavity as shown in Figure 9.

The general correlation shown in Figure 9 has been developed for vertical surfaces, but is directly applicable to an upward facing surface that is being heated by the flow [3]. Evaluating the general correlation for an air temperature of $1000^{\circ} \mathrm{C}$ and a surface size of $0.3 \mathrm{~m}$ (nominal size of the pedestal holding the gauges) gives results shown in Figure 10. 

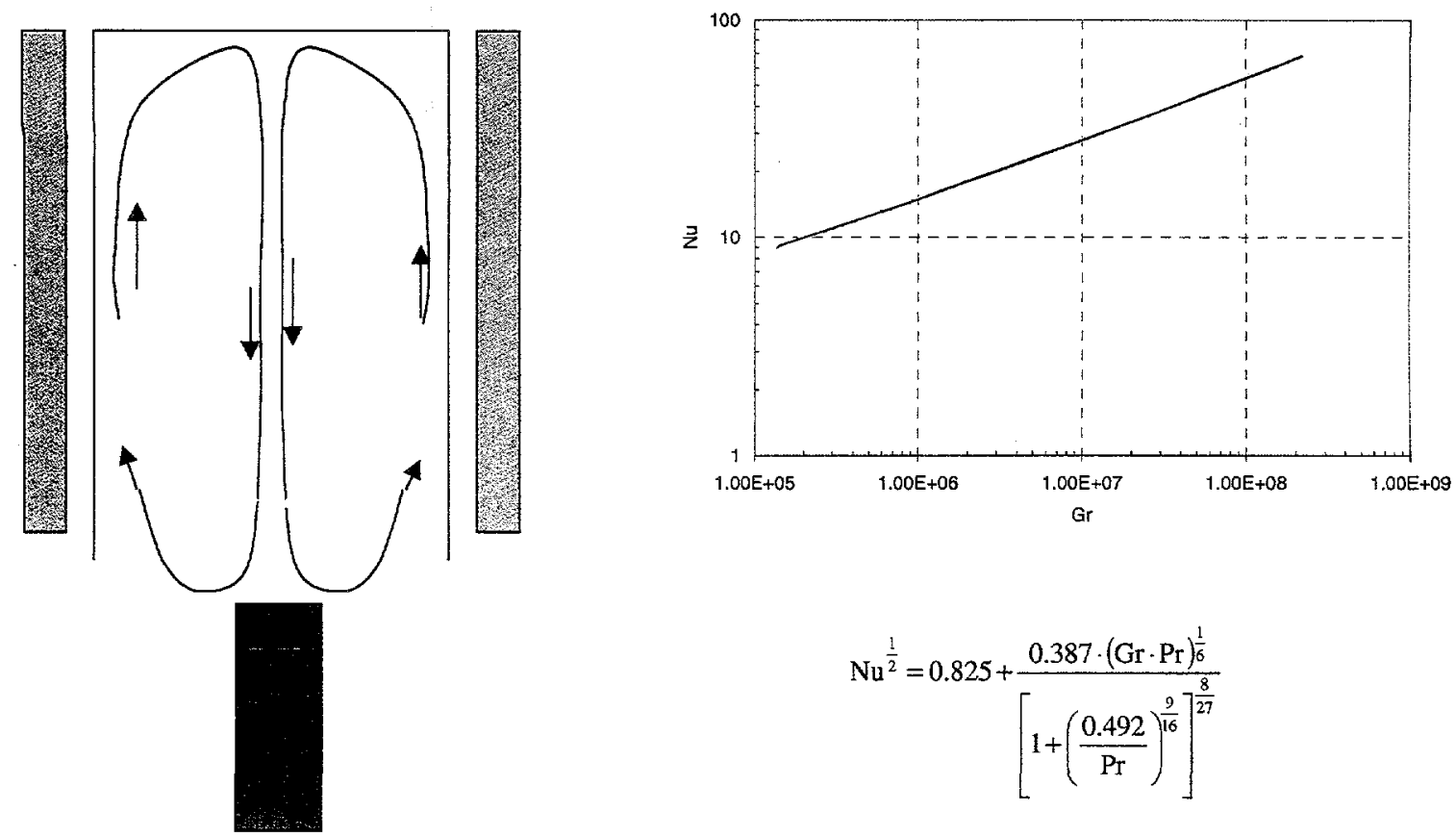

$$
\mathrm{Nu}^{\frac{1}{2}}=0.825+\frac{0.387 \cdot(\mathrm{Gr} \cdot \mathrm{Pr})^{\frac{1}{6}}}{\left[1+\left(\frac{0.492}{\mathrm{Pr}}\right)^{\frac{9}{16}}\right]^{\frac{8}{27}}}
$$

Churchill-Chu General Correlation for

Flat Plate Free Convection

Figure 9. An assumed convection cell in the test cavity results in convective heat transfer from the air to the gauges located in the mouth of the cavity.

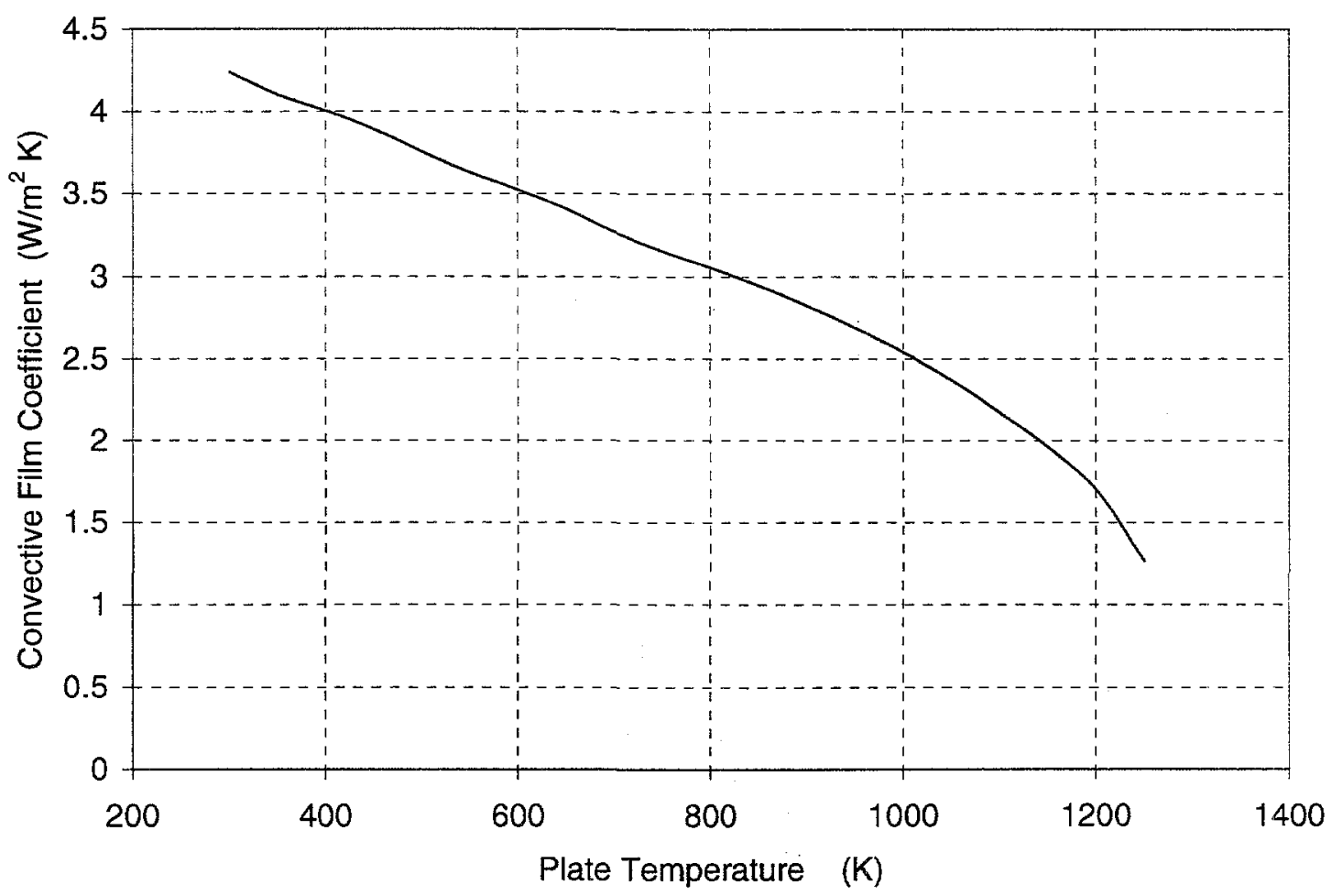

Figure 10. Estimated convective heat transfer coefficient for a surface facing up into the cavity as a function of surface temperature (air temperature $=1000^{\circ} \mathrm{C}$ ). 
For purposes in this experimentation, it is convenient to fit the results to a curve:

$$
h=\frac{(21.02-0.002144 \cdot T \cdot \ln (T))^{\frac{1}{2}}}{1000} \cdot \frac{k W}{m^{2} \cdot K} \text { for } T \text { in } K .
$$

It is worth pointing out, this curve is valid only for the experimental setup, and is not intended for use in application of the HFG in other flow situations.

\section{Radiant Heat Flux Step Input}

Figure 10 indicates that the Gardon response in the experiment can be corrected for the convective contribution by subtracting $4 \mathrm{~kW} / \mathrm{m}^{2}$, since the Gardon gauge is water cooled and operated at about $400 \mathrm{~K}$. Because the Gardon gauge is calibrated using a purely radiative source to provide a measurement of incident flux, the Gardon gauge surface absorptance $(\cong 0.85)$ has to be applied to the correction value $(4 / 0.85=4.7)$. The uncertainty in this correction value is about $50 \%$ [4]. Thus, the radiant heat flux step input to the HFG is taken to be

$$
\text { (Gardon Response - 4.7) } \pm 2.4 \mathrm{~kW} / \mathrm{m}^{2}
$$

and a plot of it is shown in Figure 11.

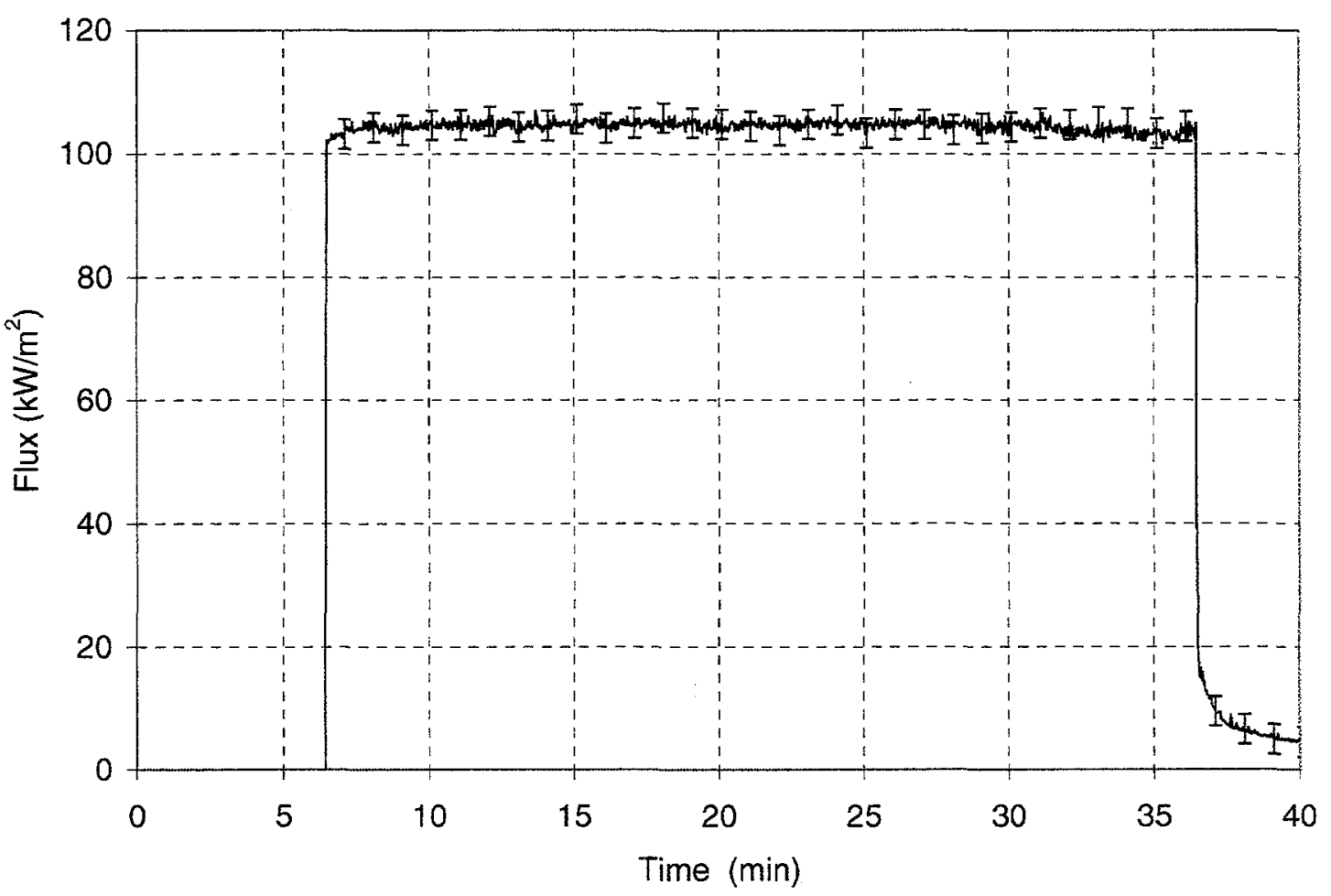

Figure 11. Step input of radiant heat flux to the HFG. 


\section{HFG Response}

The incident heat flux for the heat flux gauge test, as determined by the Gardon gauge and HFG, is plotted in Figure 12. The various heat losses to the insulation $\left(\mathrm{q}_{\mathrm{ins}} / \alpha\right)$, the sensible heat stored in the sensor plate $\left(\mathrm{q}_{\mathrm{stee}} / \alpha\right)$, heat re-radiated from the steel cover $\left(\mathrm{q}_{\mathrm{rad}}\right)$, and convective heat losses $\left(\mathrm{q}_{\text {conv }} / \alpha\right)$ for the SNL HFG are also plotted in Figure 12.

Temperature profiles calculated in the insulation for the calibration test are plotted in Figure 13. Note that for this insulation thickness, saturation has not occurred even at 1700 seconds. The numerical technique described in this paper provides a convenient means of modeling heat losses to the insulating material yielding improved agreement between measured and imposed heat flux. As seen in Figure 14, heat losses to the insulation are significant at times long after the storage term (sensible heat of the steel cover) has become negligible. By modeling heat losses to the insulation, the time response of the heat flux gauge is greatly improved. It is believed that the difference between the Gardon Gauge response and the HFG response early on $(<40 \mathrm{sec})$ is due to the thermocouple attachment to the HFG sensor plate since this is a known source of time lag and has not been accounted for in the model.

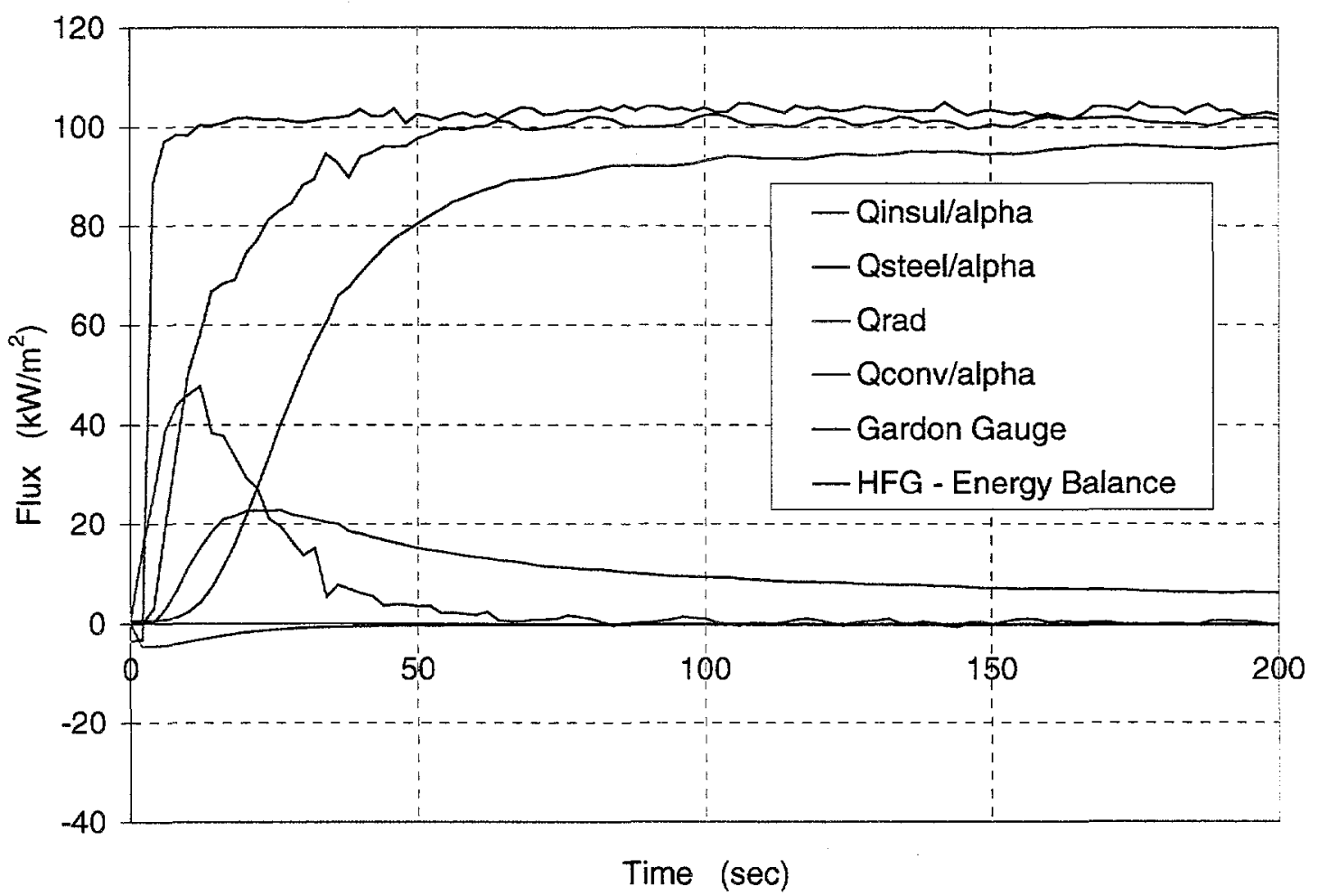

Figure 12. Measured versus calculated incident heat flux. 


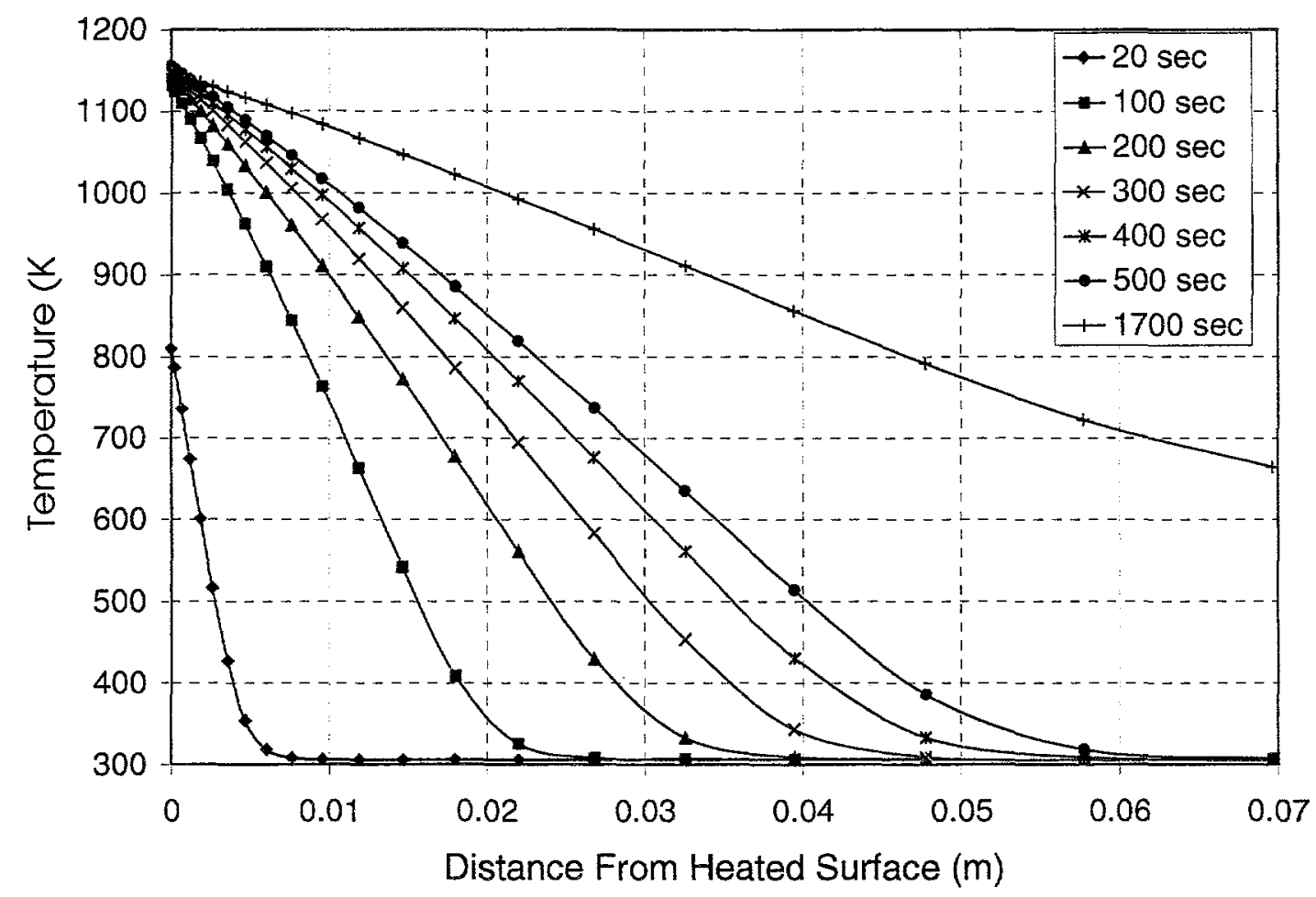

Figure 13. Calculated temperature profile in Kaowool ${ }^{\circledR}$ insulation.

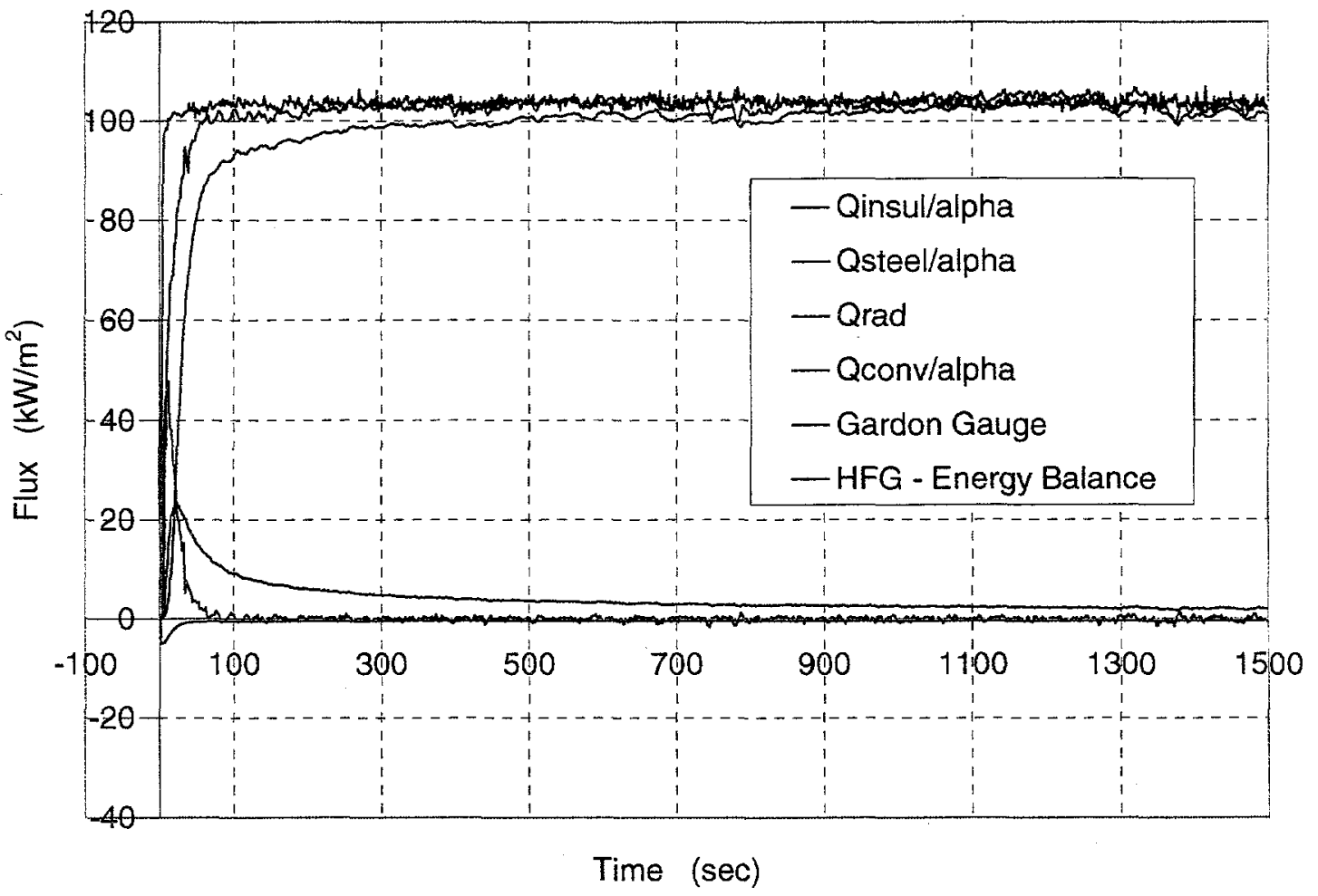

Figure 14. Long-term insulation heat loss. 


\section{UNCERTAINTY}

The uncertainty has been found to be a function of the flux level, rate of change of flux level, time, and heating history. Thus, it is not appropriate to report the uncertainty as a single percentage value, rather, it is required to report it point by point as an observational error bar. As an example, our estimate of the uncertainty of the measurement realized with the flux step input is shown in Figure 15. The measurement as determined from the response of the thermocouple via the response model is indicated with a solid blue line in that figure. The upper and lower bounds of the uncertainty are indicated with horizontal tick marks. These bounds were determined from the uncertainty model that is developed in the following sections. For comparison purposes, the input incident heat flux as recorded by the Gardon Gauge is also shown in Figure 15.

In application, the slow response of the gauge means the heat flux measurement is likely to be unreliable during and after fluctuations in flux. Nearly one minute is required before the measured flux approaches the steady state value of the step input. However, it can be seen the uncertainty is relatively large during the early times of the response to the step input, and approaches a constant value as the gauge comes to equilibrium with the step input. This can be used to advantage in assessing heat flux measurements in actual fires. Figure 1 shows a fiveminute segment of a measurement made in a $5 \mathrm{~m}$ outdoor pool fire with a HFG facing upward and located near the fuel pool surface. The heat flux varied with time during this test, presumably because of wind shifts, and is typical of most fire data. The error bars shown are calculated from the uncertainty model and their variation with the flux level, rate of change of flux level, time, and heating history are evident. Times of near constant uncertainty signal the attainment of steady-state where the measurement can be assumed valid.

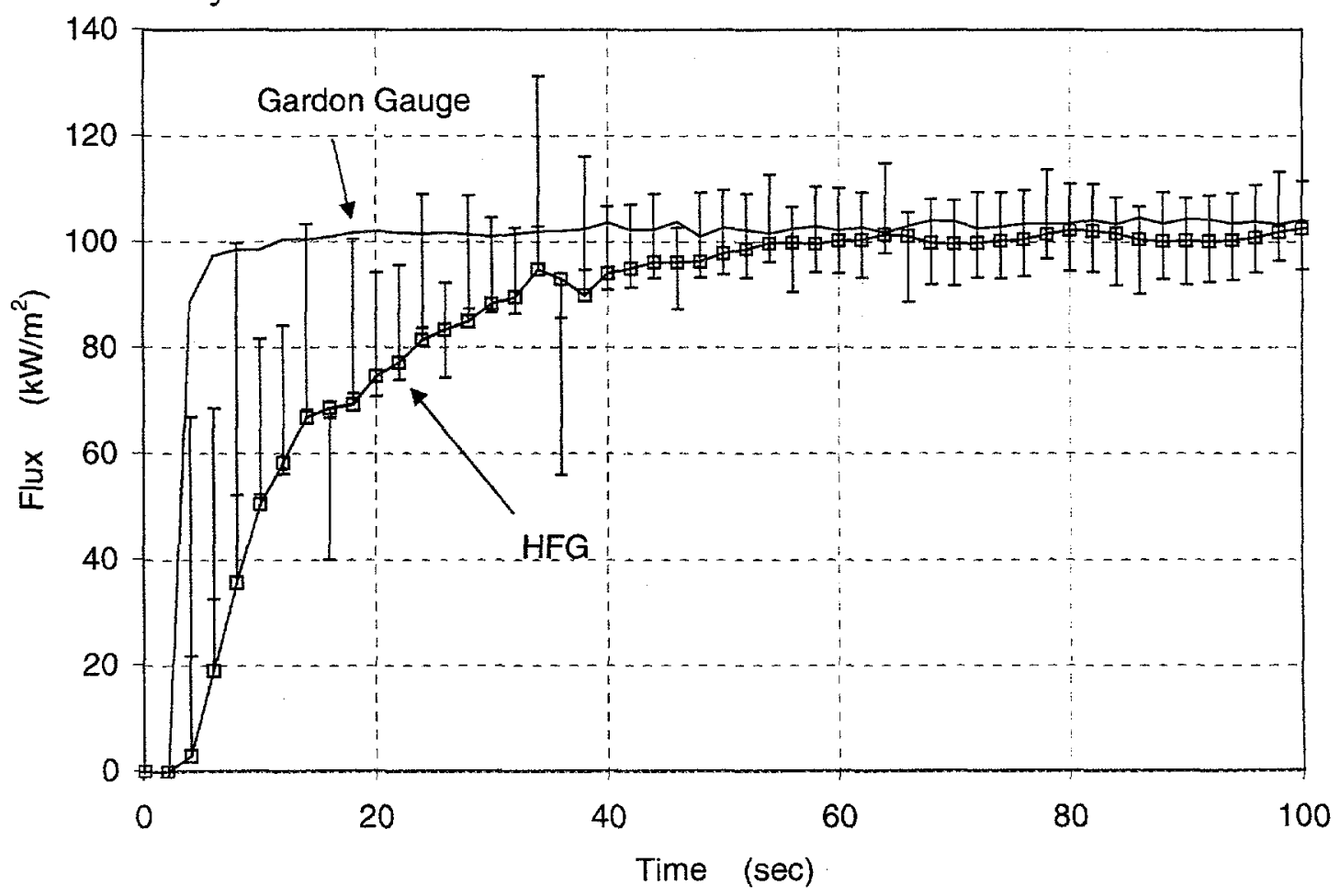

Figure 15. Estimate of the uncertainty of measurement of the step input. 


\section{Uncertainty Model}

Uncertainty in the heat flux measurement arises from: (1) uncontrolled variability in the gauge characteristics, (2) missing physics in the model, (3) and simplifying assumptions taken on in formulating the instrument response model. The uncontrolled variability includes material thermal properties, geometrical dimensions, data acquisition system hardware, thermocouple uncertainty, etc. Examples include the specific heat and thickness of the stainless steel sensor plate. Estimating uncertainty from this source is relatively straightforward, requiring only knowledge of the variability of the properties and dimensions. As for the missing physics, these phenomena are commonly buried under empirical constants that are created to bring the modeled instrument response into agreement with the observed experimental response to a known input. An example of this would be the empirically determined time constant derived to account for the thermocouple attachment to the HFG sensor plate. Simplifying assumptions include either subscale phenomena or phenomena believed to be of secondary importance. An example of the former is the assumption of no temperature gradient through the sensor plate; and of the latter, the assumption of negligible lateral conduction in the gauge. Uncertainties arising from this source are usually set to zero and justified by appealing to more complicated models or experimental evidence. Here, we adopt the same approach for the sensor plate, however, we do attempt to account for the effect of making the 1-D assumption.

\section{Uncontrolled Variability}

The uncontrolled variability includes material thermal properties and geometrical dimensions. Estimating uncertainty from these sources is straightforward by evaluating:

$$
\delta U_{U V}^{2}=\sum_{e=1}^{14}\left(\frac{\partial q_{\text {surf }}}{\partial S_{e}} \cdot \delta S_{e}\right)^{2}
$$

where the first seven sources $S_{e}$, the sensitivities $\frac{\partial q_{\text {surf }}}{\partial S_{e}}$, and the source uncertainties $\delta S_{e}$ are identified in Table 1 (the other seven sources are identified in a following section entitled Missing Physics).

The sensitivity terms in the table are obtained by performing the indicated partial differentiations on the data reduction expression

$$
\begin{aligned}
q_{\text {surf }}\left(t_{N}\right)= & \sigma \cdot\left(T_{1}^{N}\right)^{4}+\frac{q_{\text {conv }}}{\alpha}+\frac{\rho \cdot C_{p}\left(T_{1}^{N}\right) \cdot L}{\alpha} \cdot \frac{\left(-T_{1}^{N+2}+8 \cdot T_{1}^{N+1}-8 \cdot T_{1}^{N-1}+T_{1}^{N-2}\right)}{12 \cdot\left(t_{N+1}-t_{N}\right)} \\
& +\frac{q_{\text {ins }}}{\alpha} .
\end{aligned}
$$

The source term uncertainties for the first four sources are simply fixed percentages of the pertinent term. For example, the uncertainty in the sensor plate thickness $L$ is taken to $20 \%$, the uncertainty in $\rho \cdot C_{p}$ is $5 \%$, and so on. 


\begin{tabular}{|c|c|c|c|}
\hline \multicolumn{4}{|c|}{$\begin{array}{c}\text { Table } 1 \\
\text { Uncontrolled Variability as Uncertainty Sources }\end{array}$} \\
\hline$e$ & $\begin{array}{c}\text { Source } \\
S_{e}\end{array}$ & $\begin{array}{l}\text { Sensitivity } \\
\frac{\partial q_{\text {surf }}}{\partial S_{e}}\end{array}$ & $\begin{array}{l}\text { Source Uncertainty } \\
\qquad \delta S_{e}\end{array}$ \\
\hline 1 & $L$ & $\frac{\rho \cdot C_{p}\left(T_{1}^{N}\right)}{\alpha} \frac{d T_{1}^{N}}{d t}$ & $0.20 \mathrm{~L}$ \\
\hline 2 & $\rho \cdot C_{p}$ & $\frac{L}{\alpha} \frac{d T_{1}^{N}}{d t}$ & $0.05 \rho \cdot C_{p}\left(T_{1}^{N}\right)$ \\
\hline 3 & $\alpha$ & $\frac{\rho \cdot C_{p}\left(T_{1}^{N}\right) \cdot L}{\alpha^{2}} \frac{d T_{1}^{N}}{d t}$ & $0.05 \alpha$ \\
\hline 4 & $T_{1}$ & $4 \cdot \sigma \cdot\left(T_{1}^{N}\right)^{3}$ & $0.05 \cdot T_{I}^{N}$ \\
\hline 5 & $\frac{d T_{1}^{N}}{d t}$ & $\frac{\rho \cdot C_{p}\left(T_{1}^{N}\right) \cdot L}{\alpha}$ & $0.10 \cdot \sqrt{\frac{130}{144 \cdot\left(t_{N+1}-t_{N}\right)^{2}}}$ \\
\hline 6 & $\frac{q_{\text {ins }}}{\alpha}$ & 1.0 & $0.03 \cdot q_{\text {suff }}$ \\
\hline 7 & $\frac{q_{c o n v}}{\alpha}$ & 1.0 & $0.03 \cdot q_{\text {surf }}$ \\
\hline
\end{tabular}

The uncertainty of the derivative, $\frac{d T_{1}^{N}}{d t}$, is due to random noise introduced to the recorded temperature time history via the data acquisition system. The noise is constant at $0.1^{\circ} \mathrm{C}$ regardless of the temperature reading. Its impact on the uncertainty of time derivative is found from

$$
\delta\left(\frac{d T_{1}^{N}}{d t}\right)=\sqrt{\sum_{i=N-2}^{N+2}\left[\frac{\partial\left(\frac{d T_{1}^{N}}{d t}\right)}{\partial T_{1}^{i}} \cdot 0.1\right]^{2}}=\frac{0.1 \cdot \sqrt{130}}{12 \cdot\left(t_{N+1}-t_{N}\right)}
$$


For the uncertainty of the term, $\frac{q_{\text {ins }}}{\alpha}$, the data reduction model was run with $20 \%$ changes in the thermal properties of the insulating material and it was found the maximum effect on the calculated heat flux was less than $3 \%$; hence the uncertainty level has been conservatively set at the $3 \%$ value.

The uncertainty due to convection is more difficult to evaluate as it is dependant on the actual installation of the gauge in use. The flow conditions and local gas temperatures (which in practice are not known) contribute to this uncertainty. VULCAN calculations have indicated in general convective fluxes in fires are about 3\% of the radiant flux [4] although this can vary with location. Therefore, the value of $3 \%$ of the radiant flux has been adopted for the uncertainty value.

\section{Missing Physics}

These phenomena are commonly buried under empirical constants that are created to bring the modeled instrument response into agreement with the observed experimental response to a known input. An example of this would be the empirically determined time constant derived to account for the thermocouple attachment to the HFG sensor plate.

It is known the thermocouple lags the sensor plate temperature due to the thermal mass of the thermocouple and the thermal resistance between the thermocouple and the plate. An experimental evaluation of the lag was accomplished by attaching an intrinsic junction thermocouple next to the existing thermocouple and exposing the HFG to a step input. The results are shown in Figure 16. In that figure, the temperature measured by the intrinsic junction is assumed to be the sensor plate temperature. It can be seen the difference between the thermocouple reading and the plate approaches $200^{\circ} \mathrm{C}$.

Thermocouple lag is commonly corrected via a first order model that incorporates an empirical time constant.

$$
T_{\text {Plate }}=T_{T C}+\tau \cdot \frac{d T_{T C}}{d t}
$$

The value of the time constant is found by plotting the difference between the plate and thermocouple versus the time rate of change of the thermocouple reading. This is shown in Figure 17 where it can be seen the value of $\tau$ is just over 5 seconds. The correction is then applied to the thermocouple reading and shown in Figure 16.

The correction can be implemented into the data reduction scheme by substitution

$$
q_{\text {surf }}\left(t_{N}\right)=\sigma \cdot\left(T_{1}^{N}+\tau \cdot \frac{d T_{1}^{N}}{d t}\right)^{4}+\frac{q_{\text {conv }}}{\alpha}+\frac{\rho \cdot C_{p}\left(T_{1}^{N}+\tau \cdot \frac{d T_{1}^{N}}{d t}\right) \cdot L}{\alpha} \cdot \frac{d}{d t}\left(T_{l}^{N}+\tau \cdot \frac{d T_{l}^{N}}{d t}\right)+\frac{q_{\text {ins }}}{\alpha}
$$




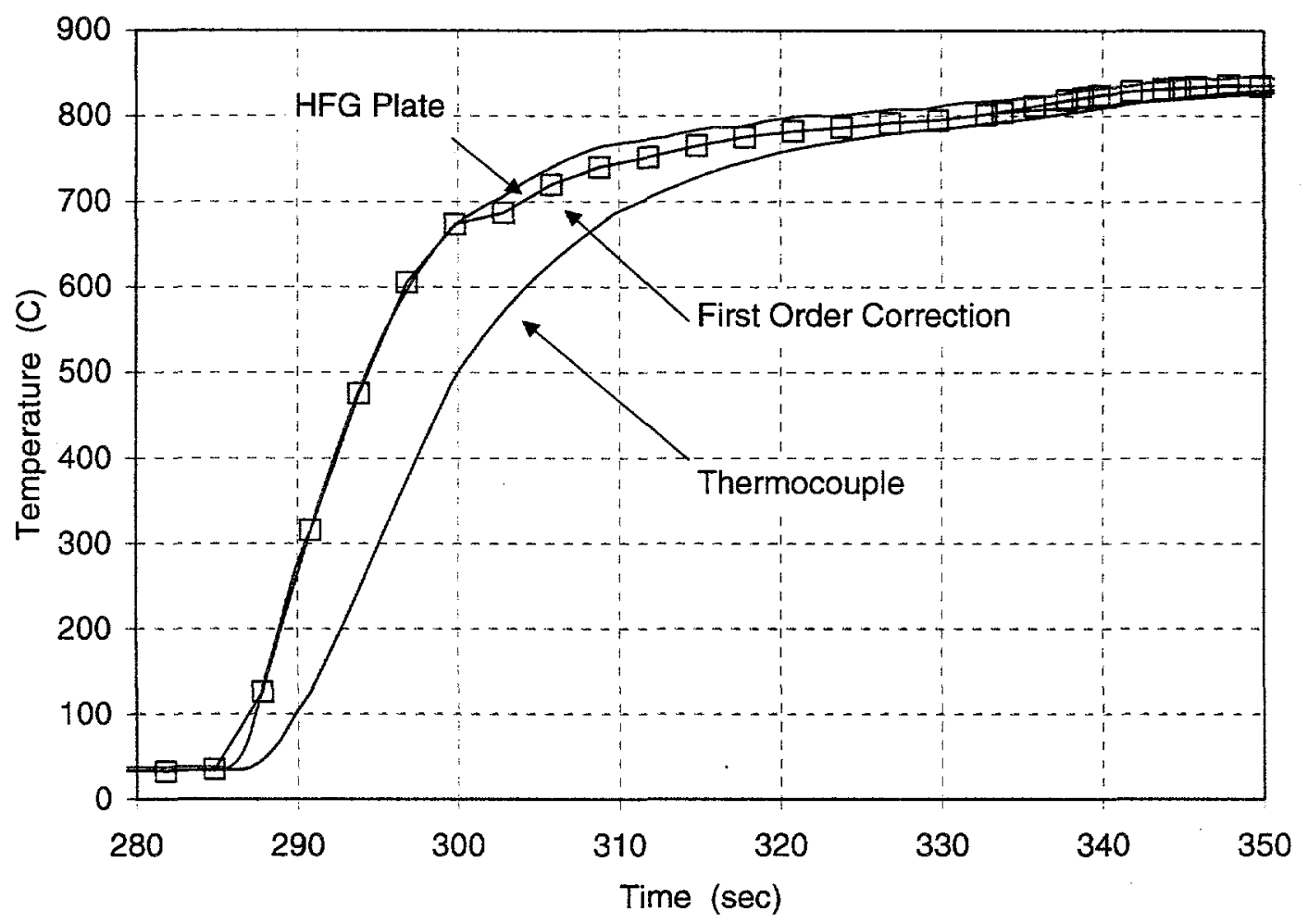

Figure 16. The thermocouple lags the actual plate temperature. The lag can be corrected with a first order model.

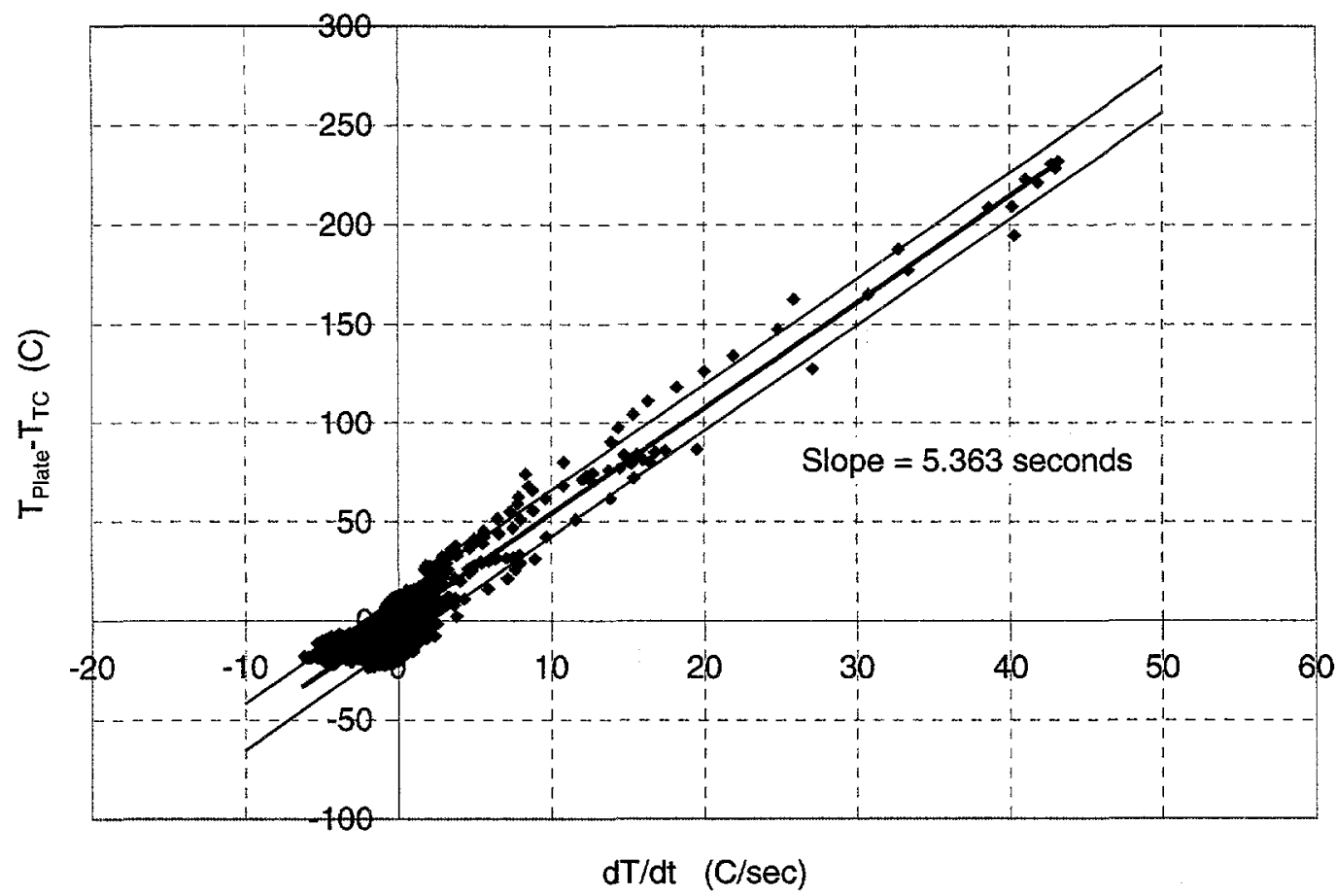

Figure 17. Experimental determination of the time constant for the first order correction to the thermocouple reading. 
which after rearranging and assuming that $\rho \cdot C_{P}\left(T_{1}^{N}+\frac{d T_{1}^{N}}{d t}\right) \approx \rho \cdot C_{P}\left(T_{1}^{N}\right)$ gives

$$
\begin{aligned}
q_{\text {surf }}\left(t_{N}\right)= & \sigma \cdot\left(T_{1}^{N}\right)^{4}+\frac{q_{\text {conv }}}{\alpha}+\frac{\rho \cdot C_{p}\left(T_{1}^{N}\right) \cdot L}{\alpha} \cdot \frac{d T_{1}^{N}}{d t}+\frac{q_{\text {ins }}}{\alpha} \\
& +\frac{\rho \cdot C_{p}\left(T_{1}^{N}\right) \cdot L}{\alpha} \cdot \tau \cdot \frac{d^{2} T_{1}^{N}}{d t^{2}}+\sigma \cdot\left[4 \cdot\left(T_{1}^{N}\right)^{3} \cdot \tau \cdot \frac{d T_{1}^{N}}{d t}+6 \cdot\left(T_{1}^{N}\right)^{2} \cdot \tau^{2} \cdot\left(\frac{d T_{1}^{N}}{d t}\right)^{2}\right] \\
& +\sigma \cdot\left[4 \cdot T_{1}^{N} \cdot \tau^{3} \cdot\left(\frac{d T_{1}^{N}}{d t}\right)^{3}+\tau^{4} \cdot\left(\frac{d T_{1}^{N}}{d t}\right)^{4}\right]
\end{aligned}
$$

which is seen to be the original response model plus a systematic correction for the thermocouple installation.

Normally, the systematic correction would be included in the response model. Here, we choose to put the correction in the uncertainty because it is based on $\tau$, an empirical constant that covers the missing physics for the thermocouple installation. Therefore, a systematic error term for the missing physics is defined:

$$
\begin{aligned}
\delta U_{M P}= & \frac{\rho \cdot C_{p}\left(T_{1}^{N}\right) \cdot L}{\alpha} \cdot \tau \cdot \frac{d^{2} T_{1}^{N}}{d t^{2}}+\sigma \cdot\left[4 \cdot\left(T_{1}^{N}\right)^{3} \cdot \tau \cdot \frac{d T_{1}^{N}}{d t}+6 \cdot\left(T_{1}^{N}\right)^{2} \cdot \tau^{2} \cdot\left(\frac{d T_{1}^{N}}{d t}\right)^{2}\right] \\
& +\sigma \cdot\left[4 \cdot T_{1}^{N} \cdot \tau^{3} \cdot\left(\frac{d T_{1}^{N}}{d t}\right)^{3}+\tau^{4} \cdot\left(\frac{d T_{1}^{N}}{d t}\right)^{4}\right] .
\end{aligned}
$$

The uncontrolled variance of the different sources enter into the total uncertainty via this error term as well. Table 2 shows the sources, sensitivities, and source term uncertainties as the remaining six entries for the total uncontrolled uncertainty expression.

The sensitivities and source uncertainties are, as before, with only the time constant and the second derivative being new terms. The second derivative is approximated from a five-point central difference scheme as:

$$
\frac{d^{2} T_{1}^{N}}{d t}=\frac{-T_{1}^{N+2}+16 \cdot T_{1}^{N+1}-30 \cdot T_{1}^{N}+16 \cdot T_{1}^{N-1}-T_{1}^{N-2}}{12 \cdot\left(t_{N+1}-t_{N}\right)^{2}}
$$

which allows the source term uncertainty to be calculated as explained in the previous section. 


\begin{tabular}{|c|c|c|c|}
\hline \multicolumn{4}{|c|}{$\begin{array}{c}\text { Table } 2 \\
\begin{array}{c}\text { Uncontrolled Variability as Uncertainty Sources } \\
\text { from the Systematic Error Term }\end{array}\end{array}$} \\
\hline$e$ & $\begin{array}{l}\text { Source } \\
S_{e}\end{array}$ & $\begin{array}{l}\text { Sensitivity } \\
\frac{\partial q_{\text {surf }}}{\partial S_{e}}\end{array}$ & $\begin{array}{c}\text { Source Uncertainty } \\
\delta S_{e}\end{array}$ \\
\hline 8 & $L$ & $\frac{\rho \cdot C_{p}\left(T_{1}^{N}\right)}{\alpha} \cdot \tau \cdot \frac{d^{2} T_{1}^{N}}{d t^{2}}$ & $0.20 \mathrm{~L}$ \\
\hline 9 & $\rho \cdot C_{p}$ & $\frac{L}{\alpha} \cdot \tau \cdot \frac{d^{2} T_{1}^{N}}{d t^{2}}$ & $0.05 \rho \cdot C_{p}\left(T_{1}^{N}\right)$ \\
\hline 10 & $T_{1}$ & $\begin{array}{l}\sigma \cdot\left[12 \cdot\left(T_{1}^{N}\right)^{2} \cdot \tau \cdot \frac{d T_{1}^{N}}{d t}\right] \\
+\sigma \cdot\left[12 \cdot T_{1}^{N} \cdot \tau^{2} \cdot\left(\frac{d T_{1}^{N}}{d t}\right)^{2}+4 \cdot \tau^{3} \cdot\left(\frac{d T_{1}^{N}}{d t}\right)^{3}\right]\end{array}$ & $0.05 \cdot T_{I}^{N}$ \\
\hline 11 & $\frac{d T_{l}^{N}}{d t}$ & $\begin{array}{l}\sigma \cdot\left[4 \cdot\left(T_{1}^{N}\right)^{3} \cdot \tau+12 \cdot\left(T_{1}^{N}\right)^{2} \cdot \tau^{2} \cdot \frac{d T_{1}^{N}}{d t}\right] \\
+\sigma \cdot\left[12 \cdot T_{1}^{N} \cdot \tau^{3} \cdot\left(\frac{d T_{1}^{N}}{d t}\right)^{2}+4 \cdot \tau^{4} \cdot\left(\frac{d T_{1}^{N}}{d t}\right)^{3}\right]\end{array}$ & $0.10 \cdot \sqrt{\frac{130}{144 \cdot\left(t_{N+1}-t_{N}\right)^{2}}}$ \\
\hline 12 & $\tau$ & $\begin{array}{l}\frac{\rho \cdot C_{p}\left(T_{1}^{N}\right) \cdot L}{\alpha} \cdot \frac{d^{2} T_{1}^{N}}{d t^{2}}+\sigma \cdot\left[4 \cdot\left(T_{1}^{N}\right)^{3} \cdot \frac{d T_{1}^{N}}{d t}\right] \\
+\sigma \cdot\left[12 \cdot\left(T_{1}^{N}\right)^{2} \cdot \tau \cdot\left(\frac{d T_{1}^{N}}{d t}\right)^{2}\right] \\
+\sigma \cdot\left[12 \cdot T_{1}^{N} \cdot \tau^{2} \cdot\left(\frac{d T_{1}^{N}}{d t}\right)^{3}+4 \cdot \tau^{3} \cdot\left(\frac{d T_{1}^{N}}{d t}\right)^{4}\right]\end{array}$ & $0.50 \cdot \tau$ \\
\hline 13 & $\frac{d^{2} T_{1}^{N}}{d t^{2}}$ & $\frac{\rho \cdot C_{p}\left(T_{1}^{N}\right) \cdot L}{\alpha} \cdot \tau$ & $0.10 \cdot \sqrt{\frac{1414}{144 \cdot\left(t_{N+1}-t_{N}\right)^{4}}}$ \\
\hline 14 & $\alpha$ & $-\frac{\rho \cdot C_{p}\left(T_{1}^{N}\right) \cdot L}{\alpha^{2}} \cdot \tau \cdot \frac{d^{2} T_{i}^{N}}{d t^{2}}$ & $0.05 \cdot \alpha$ \\
\hline
\end{tabular}




\section{Simplifying Assumptions}

Simplifying assumptions include either sub-scale phenomena or phenomena believed to be of secondary importance. Three assumptions have been adopted in formulating the gauge thermal response model: (1) negligible temperature gradient through the sensor plate, (2) the sensor plate surface emissivity and absorptivity are the same, i.e. $\frac{\varepsilon}{\alpha}=1$, and (3) the heat conduction within the gauge is adequately modeled as 1-D. Uncertainties arising from these sources are usually set to zero and justified by appealing to more complicated models or experimental evidence. Here, we adopt this same approach for the sensor plate gradient, however, we do attempt to account for the effect of equating $\varepsilon$ and $\alpha$, and for making the 1-D assumption.

The effect of assuming the sensor is a lumped thermal mass is found by analyzing the dynamic response of a semi-infinite wall [5]. For Biot numbers less than 0.1, all temperatures through the thickness of the plate will be within a percentage $f$ percent of the sensor plate temperature

where

$$
f=50 \cdot \text { Biot } \% \text { of } T_{N}^{1}
$$

and

$$
\text { Biot }=\frac{h \cdot L}{k_{s}} \quad \text { with } \quad h \approx 4 \cdot \sigma \cdot\left(T_{N}^{l}\right)^{3}
$$

and $k_{s}$ is the thermal conductivity of the sensor plate. This leads to

$$
f\left(T_{N}^{l}\right)=50 \cdot \frac{4 \cdot \sigma \cdot\left(T_{N}^{l}+273\right)^{3} \cdot L}{k_{s}} \%
$$

being the uncertainty of $T_{N}^{l}$ due to the lumped mass assumption. To evaluate the expression, $k_{s}$ is set to $0.03 \mathrm{~kW} / \mathrm{m} \mathrm{K}$ (nominal value for stainless steel) and $L$ to $0.000254 \mathrm{~m}$. For the worst case condition, $T_{N}^{l} \approx 1000^{\circ} \mathrm{C}, f\left(T_{N}^{l}\right) \approx 0.2 \%$, and there is no appreciable contribution to the uncertainty from the assumption of no temperature gradient through the sensor plate.

The assumption of equal $\varepsilon$ and $\alpha$ is evaluated from;

$$
q_{\text {surf }}(t)=\frac{\varepsilon}{\alpha} \cdot q_{\text {rad }}(t)+\frac{q_{\text {conv }}(t)+q_{\text {steel }}(t)+q_{\text {insul }}(t)}{\alpha}
$$

where the sensitivity is found to be:

$$
\frac{\partial q_{\text {surf }}(t)}{\partial\left(\frac{\varepsilon}{\alpha}\right)}=q_{\text {rad }}(t)=\sigma \cdot\left(T_{1}^{N}\right)^{4}
$$


The uncertainty in the ratio, $\delta\left(\frac{\varepsilon}{\alpha}\right)$, is estimated from measurements made on the normal emittance of Pyromark Black [6], the coating on the fire side of the sensor plate. Figure 18 shows that data, and it can be seen that the uncertainty in the ratio (i.e. hot source/cold surface or cold source/hot surface) is about $4 \%$.

The systematic correction for the missing physics also generates an additional term to the simplifying assumptions uncertainty due to the ratio $\frac{\mathcal{E}}{\alpha}$. This additional term is included in the summary of the total uncertainty shown in Table 3.

To investigate the third assumption, time histories of two thermocouples installed in the insulation along the centerline of the gauge were recorded in the validation experiment. In comparing their response to the step input, it was noted that a 2-D conduction model gave better comparisons. However, the resulting flux from the front sensor plate was at most $5 \%$ higher than the flux determined from the 1-D model.

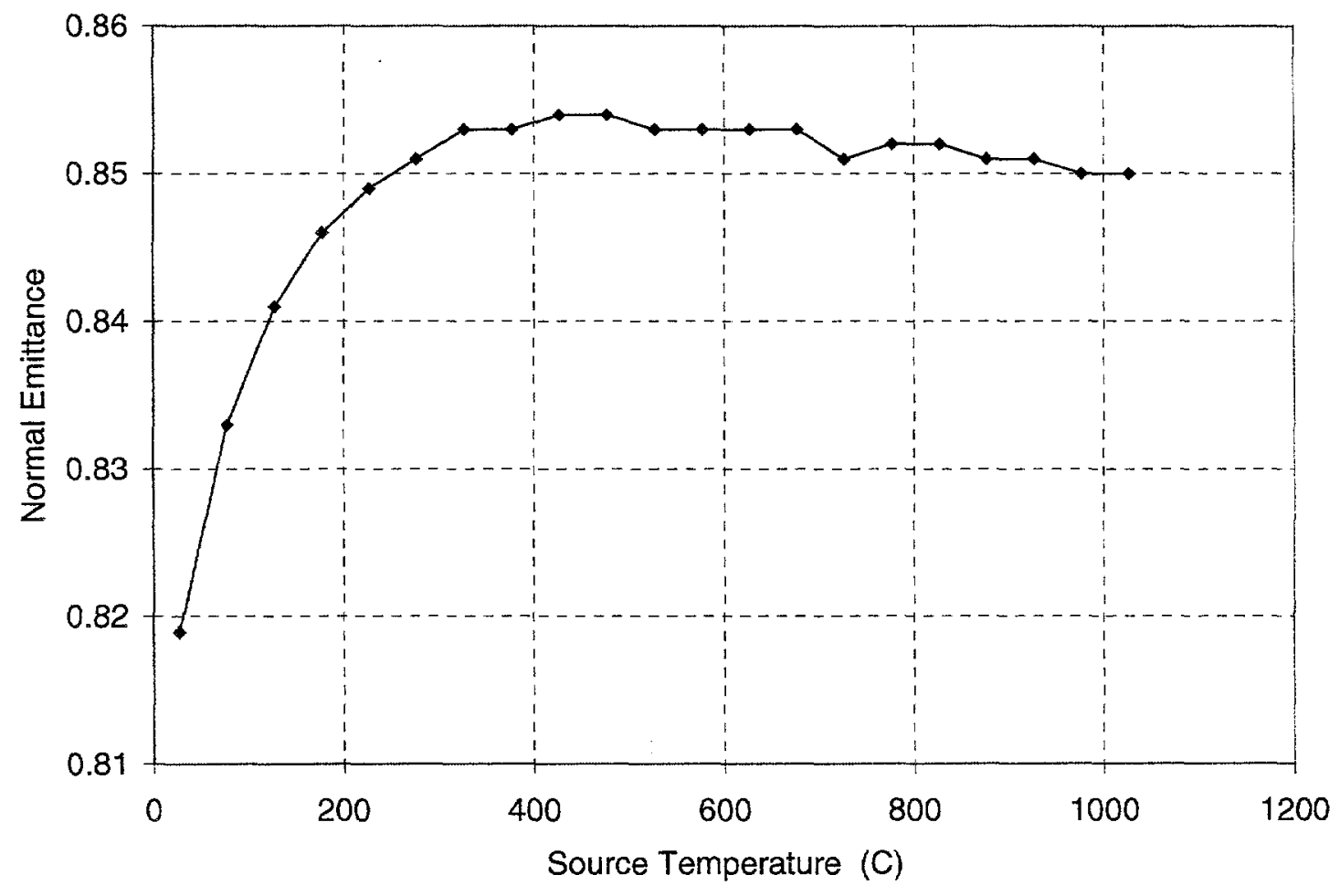

Figure 18. The normal emittance of Pyromark as a function of source temperature [6]. 
Table 3

Simplifying Assumptions as Uncertainty Sources

\begin{tabular}{|c|c|c|c|}
\hline$e$ & Source & Sensitivity & $\begin{array}{c}\text { Source } \\
\text { Uncertainty } \\
\delta S_{e}\end{array}$ \\
\hline 15 & $\left(\frac{\varepsilon}{\alpha}\right)$ & $\frac{\partial q_{\text {suff }}}{\partial S_{e}}$ & $\sigma \cdot\left(T_{1}^{N}\right)^{4}$ \\
\hline 16 & $\left(\frac{\varepsilon}{\alpha}\right)$ & $\sigma \cdot\left[4 \cdot\left(T_{1}^{N}\right)^{3} \cdot \tau \cdot \frac{d T_{1}^{N}}{d t}+6 \cdot\left(T_{1}^{N}\right)^{2} \cdot \tau^{2} \cdot\left(\frac{d T_{1}^{N}}{d t}\right)^{2}\right]$ & $0.04 \cdot\left(\frac{\varepsilon}{\alpha}\right)$ \\
\hline 17 & $1-D$ & $+\sigma \cdot\left[4 \cdot T_{1}^{N} \cdot \tau^{3} \cdot\left(\frac{d T_{1}^{N}}{d t}\right)^{3}+\tau^{4} \cdot\left(\frac{d T_{1}^{N}}{d t}\right)^{4}\right]$ & \\
\hline
\end{tabular}

In the interest of parsimony, it was decided to maintain the 1-D model and add 5\% to the uncertainty to account for the assumption. Thus, the total uncertainty for the simplifying assumptions becomes:

$$
\delta U_{S A}^{2}=\sum_{e=14}^{16}\left(\frac{\partial q_{\text {surf }}}{\partial S_{e}} \cdot \delta S_{e}\right)^{2}
$$

\section{Application to Validation Experiment}

The expression for the total uncertainty is given as

$$
\delta U=\delta U_{M P} \pm \sqrt{\delta U_{U V}^{2}+\delta U_{S A}^{2}}
$$

where:

$$
\begin{aligned}
\delta U_{M P}= & \frac{\rho \cdot C_{p}\left(T_{1}^{N}\right) \cdot L}{\alpha} \cdot \tau \cdot \frac{d^{2} T_{1}^{N}}{d t^{2}}+\sigma \cdot\left[4 \cdot\left(T_{1}^{N}\right)^{3} \cdot \tau \cdot \frac{d T_{1}^{N}}{d t}+6 \cdot\left(T_{1}^{N}\right)^{2} \cdot \tau^{2} \cdot\left(\frac{d T_{1}^{N}}{d t}\right)^{2}\right] \\
& +\sigma \cdot\left[4 \cdot T_{1}^{N} \cdot \tau^{3} \cdot\left(\frac{d T_{1}^{N}}{d t}\right)^{3}+\tau^{4} \cdot\left(\frac{d T_{1}^{N}}{d t}\right)^{4}\right]
\end{aligned}
$$


and

$$
\delta U_{U V}^{2}=\sum_{e=1}^{14}\left(\frac{\partial q_{\text {surf }}}{\partial S_{e}} \cdot \delta S_{e}\right)^{2}
$$

and

$$
\delta U_{S A}^{2}=\sum_{e=15}^{17}\left(\frac{\partial q_{s u f f}}{\partial S_{e}} \cdot \delta S_{e}\right)^{2}
$$

The relative importance of each source varies with time and are shown in Figure 19. In that figure, it can be seen at early times, the uncertainty due to the missing physics of thermocouple installation and the variability in the thickness of the sensor plate dominate. At later times when steady state is reached, the error due to the simplifying assumptions and the uncontrolled variability are most important. Referring back to Figure 15, it is of interest to see that during fast rise of the thermocouple, the uncertainty bars do not capture the reported "measured value." The same effect can also be seen in Figure 1. It can be deduced that this behavior is due to the correction term from the missing physics uncertainty.

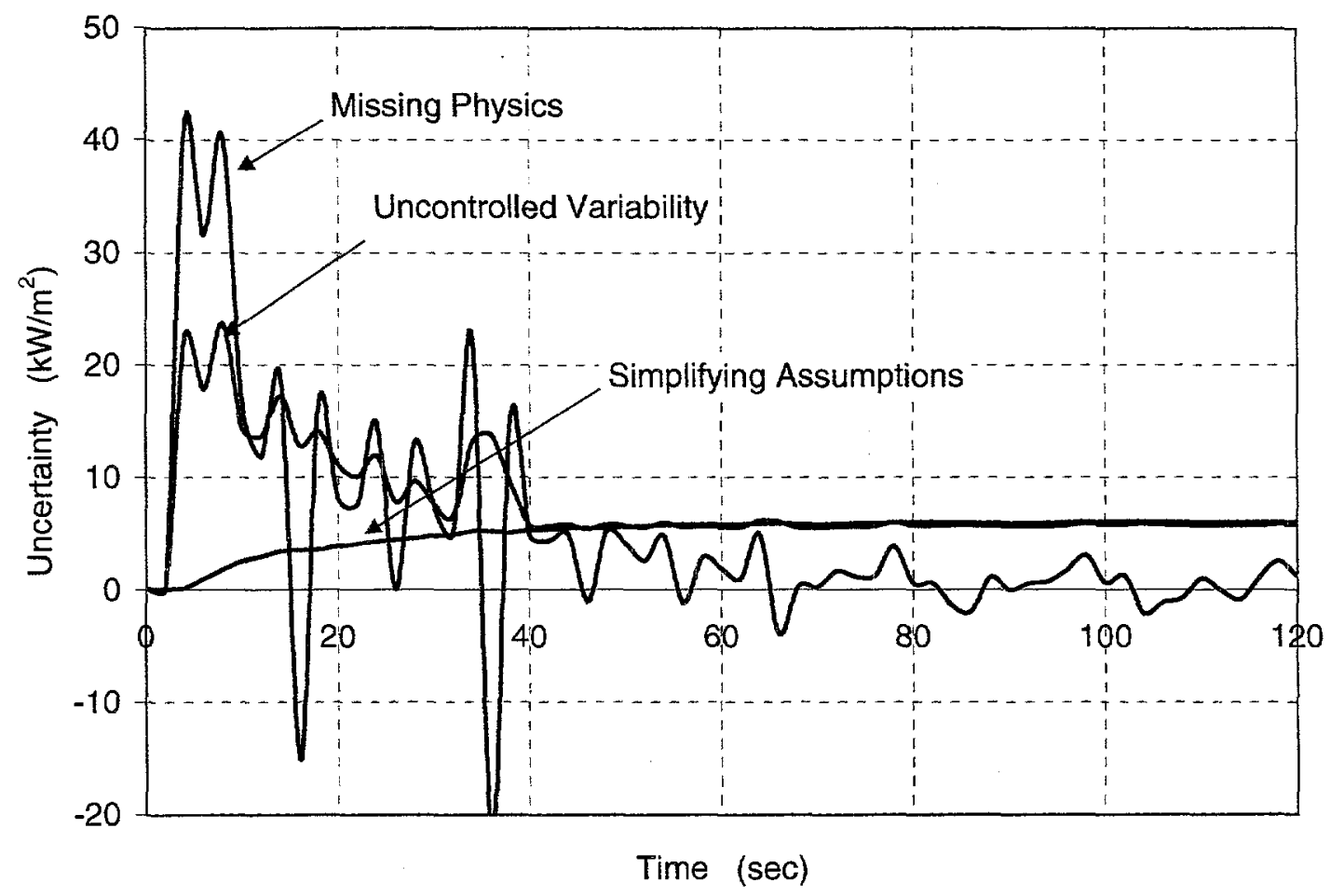

Figure 19. Relative importance of the different sources of uncertainty during a step input of 100 $\mathrm{kW} / \mathrm{m}^{2}$. 


\section{Effect of Sampling Frequency on Calculated Error}

The heat flux was calculated for the model validation experiment at three different sampling frequencies. The results, plotted in Figure 20 and Figure 21 indicate that the calculated heat flux and the associated error are dependent on the sampling frequency. The sampling frequency exercises effect in two ways. First, before the step change in heat flux, the 4-second and 6second sampling curves predict heat fluxes in advance of the Gardon gauge. This is because the time derivative uses data subsequent to the step change in heat flux in determining the temperature derivative. This 'prediction' in the model is observed in the calculated uncertainty for these curves. The second effect appears later in time. As temperatures rise from the imposed heat flux, the 2-second sampling curve shows much larger oscillations in the calculated heat flux. This is reflected as increased uncertainty during the temperature rise. Both effects disappear at steady state; all three curves show agreement and the uncertainty becomes independent of the sampling rate.

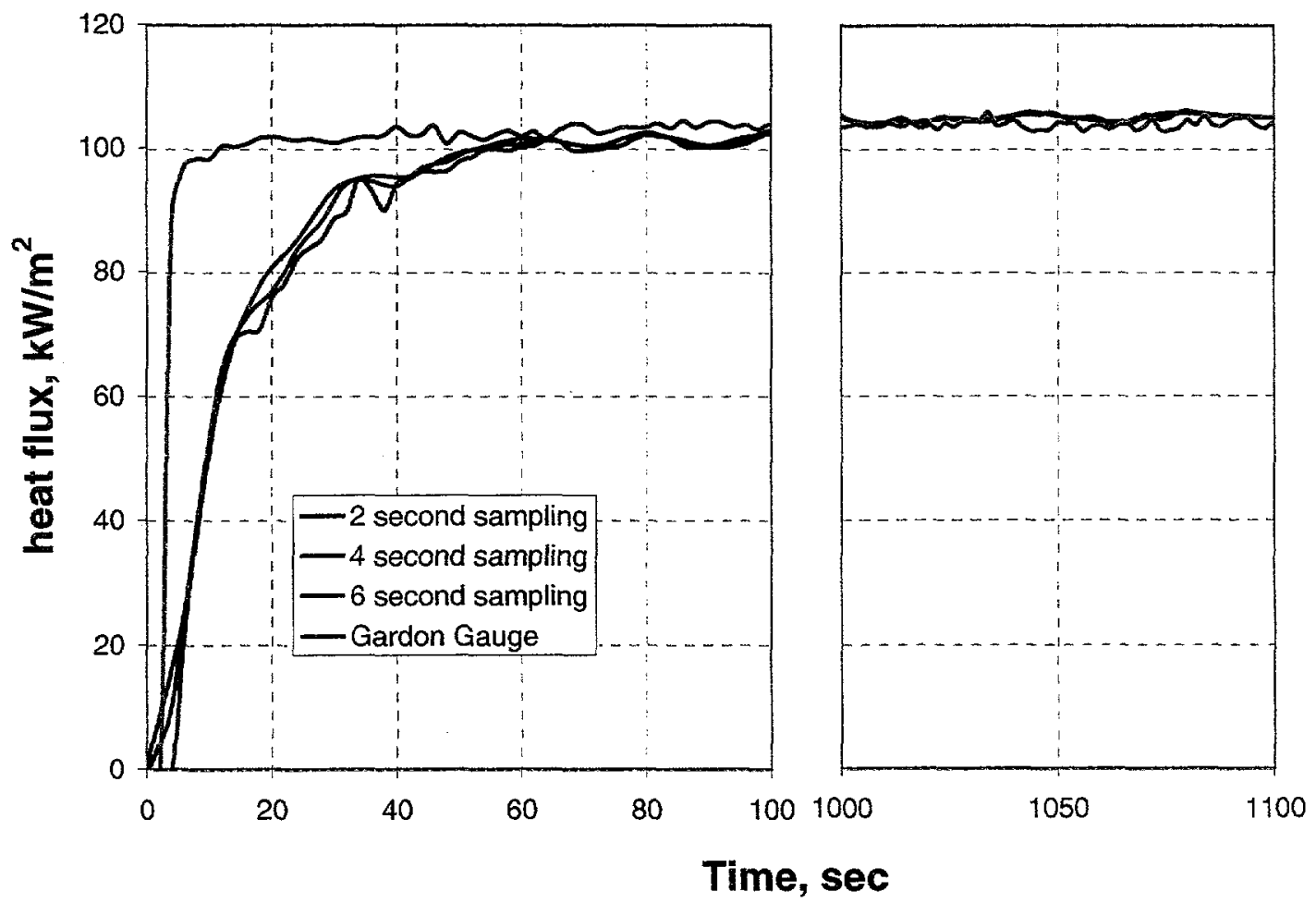

Figure 20. Heat flux calculated for various sampling frequencies. 


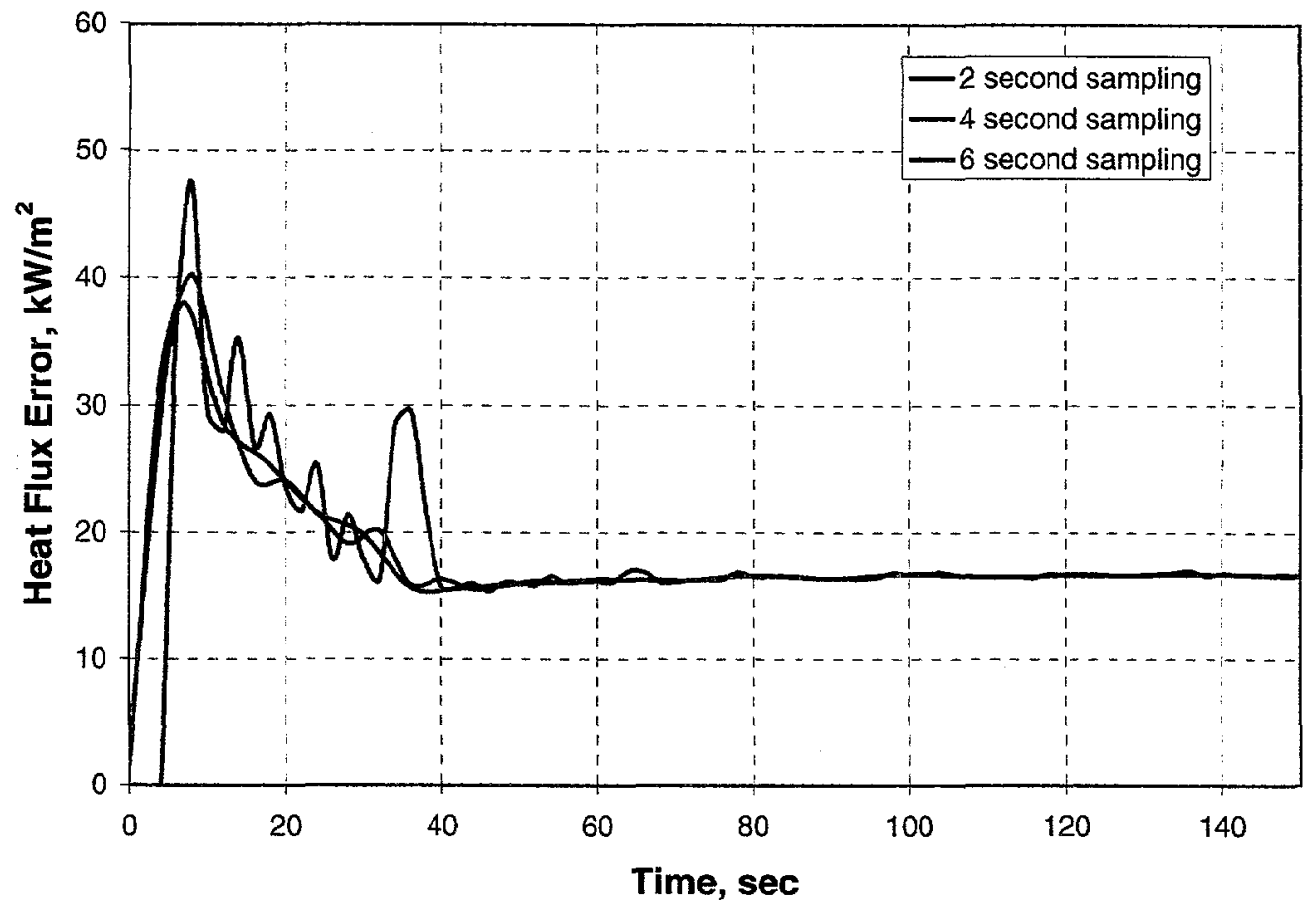

Figure 21. Heat flux error range calculated for various sampling frequencies.

The source of the uncertainty associated with sampling rate during high rates of change is the uncertainty contribution from the time derivative. This can be seen by considering a simple 3 point central difference equation for the time derivative of temperature,

$$
\frac{d T}{d t}=\frac{\left(T_{N+1}-T_{N-1}\right)}{\left(t_{N+1}-t_{N)}\right.}
$$

The equation for the associated uncertainty would be given by:

$$
\delta\left(\frac{d T_{1}^{N}}{d t}\right)=\sqrt{\sum_{i=N-2}^{N+2}\left[\frac{\partial\left(\frac{d T_{1}^{N}}{d t}\right)}{\partial T_{1}^{i}} \cdot 0.1\right]^{2}}=\frac{\sigma_{T} \cdot \sqrt{2}}{\left(t_{N+1}-t_{N}\right)}
$$

Note that as the sampling frequency increases, (or $t_{N+1}-t_{N}$ decreases), the uncertainty in the time derivative also increases. The equation for the derivative is based on differences from discretely measured values of temperatures, each with statistical uncertainty that does not depend on the time step size. Therefore the noise associated with thermocouple measurement can result in excessive error in the derivative term for small time steps. 
To reduce some of this error, the raw data can be filtered. In fact, the five-point central difference expression for computing the derivative used in this model represents such an error reduction technique. The error associated with the 5-point central difference equation,

$$
\delta\left(\frac{d T_{1}^{N}}{d t}\right)=\sqrt{\sum_{i=N-2}^{N+2}\left[\frac{\partial\left(\frac{d T_{1}^{N}}{d t}\right)}{\partial T_{1}^{i}} \cdot 0.1\right]^{2}}=\frac{\sigma_{T} \cdot \sqrt{130}}{12 \cdot\left(t_{N+1}-t_{N}\right)}
$$

is $33 \%$ less than the three-point central difference equation. However, the price for smoothing is an increase in the "prediction" source, as the 5 point central difference will anticipate changes in rise rate.

In the final analysis, the sampling rate should be commensurate with the expected temperature rise rate and the end use of the time derivative. This is to say, the data sampling rate is an important parameter in the design and use of these heat flux gauges and merits special attention prior to incorporating them in any experiment.

\section{CLOSURE}

It has been seen that the HFG is essentially a thin metal plate that responds to heating from the fire environment. A thermal model that describes the response has been advanced and it was shown how to determine the heat flux from the fire environment via the time-temperature history of the thin metal plate. A validation experiment was presented where the gauge was exposed to a step input of radiant heat flux. Comparison of the incident flux determined from the thermal model with the known flux input showed the gauge exhibited a noticeable time lag. The uncertainty of the measurement was analyzed, and an uncertainty model was put forth using the data obtained from the experiment. An empirical constant was found that compensated for the gauge time lag. This compensation was incorporated into the uncertainty model instead of the response model. As a result, the uncertainty does not capture the measurement at certain times due to the systematic error created by the missing physics.

We believe the missing physics model is incomplete and are not willing to include it in the response model. The out-of-bounds response is a signal to the user that the measurement is likely to be wrong because of the thermocouple installation. An example can be seen in Figure 1. There are alternating periods of rapidly changing heat flux and periods of steady heat flux. The uncertainty bars clearly show when it would be appropriate to use the data and when it would be better to ignore it.

If it were desirable to reduce the uncertainty, clearly the missing physics needs to be corrected. We do not believe that complicating the model with a detailed heat transfer analysis of the thermocouple installation is appropriate. The HFG should be modified so it physically meets the assumptions in the model. The obvious first step would be to replace the existing thermocouple with a fine wire intrinsic junction. 
It is also felt that the early time discrepancy may be due in part to inadequate thermal properties of the insulation. These properties were developed from steady state measurements where small temperature differences are imposed across a known thickness. It is not known if properties determined this way are appropriate in dynamic heating situations with high gradients. A different insulation material may be more appropriate. Experiments, similar to the model validation step input test, will be required to verify improved response using the suggested design modifications and to revise the uncertainty model.

\section{REFERENCES}

1. Incropera, F., and D. DeWitt, Fundamentals of Heat and Mass Transfer, John Wiley \& Sons, Inc., New York, 1995.

2. Verner, D., and T.K. Blanchat, Sandia Heat Flux Gage Calibration Experiment, Sandia National Laboratories, Albuquerque, NM 87185, August 1998.

3. White, F. M., Heat and Mass Transfer, Addison Wesley, New York, 1988.

4. Nicolette, V., Private Communication, Org. 9116, Sandia National Laboratories, Albuquerque, NM.

5. Kreith, F., Principles of Heat Transfer, Intext Educational Publishers, New York, 1976.

6. Longenbaugh, R.S., L.C. Sanchez, and A.R. Mahoney, Thermal Response of a Small CaskLike Test Article to Three Different High Temperature Environments, SAND88-0661, Sandia National Laboratories, Albuquerque, NM, 1988. 


\section{APPENDIX A}

SNL Hemispherical Heat Flux Gauge Assembly and Construction Details 


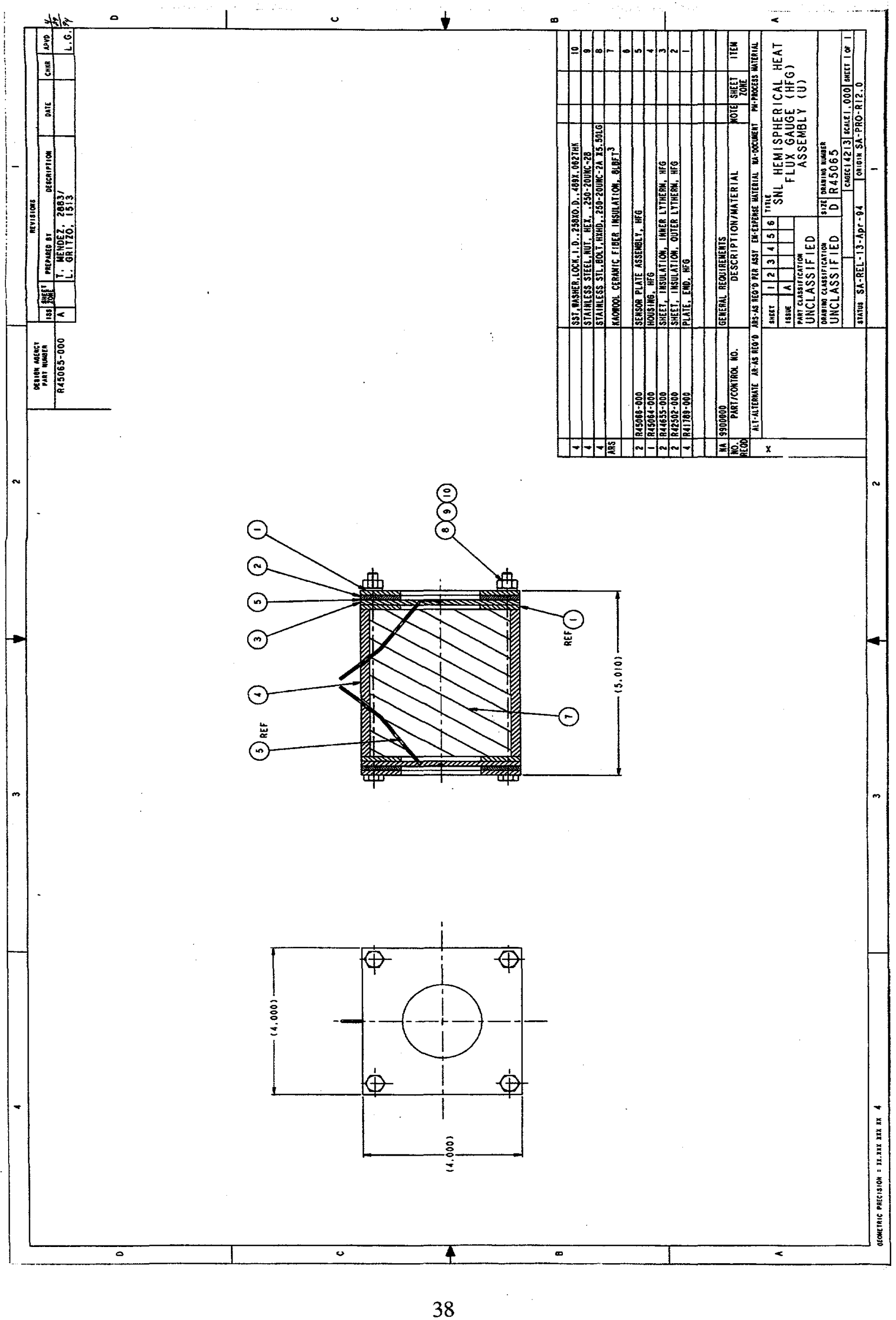




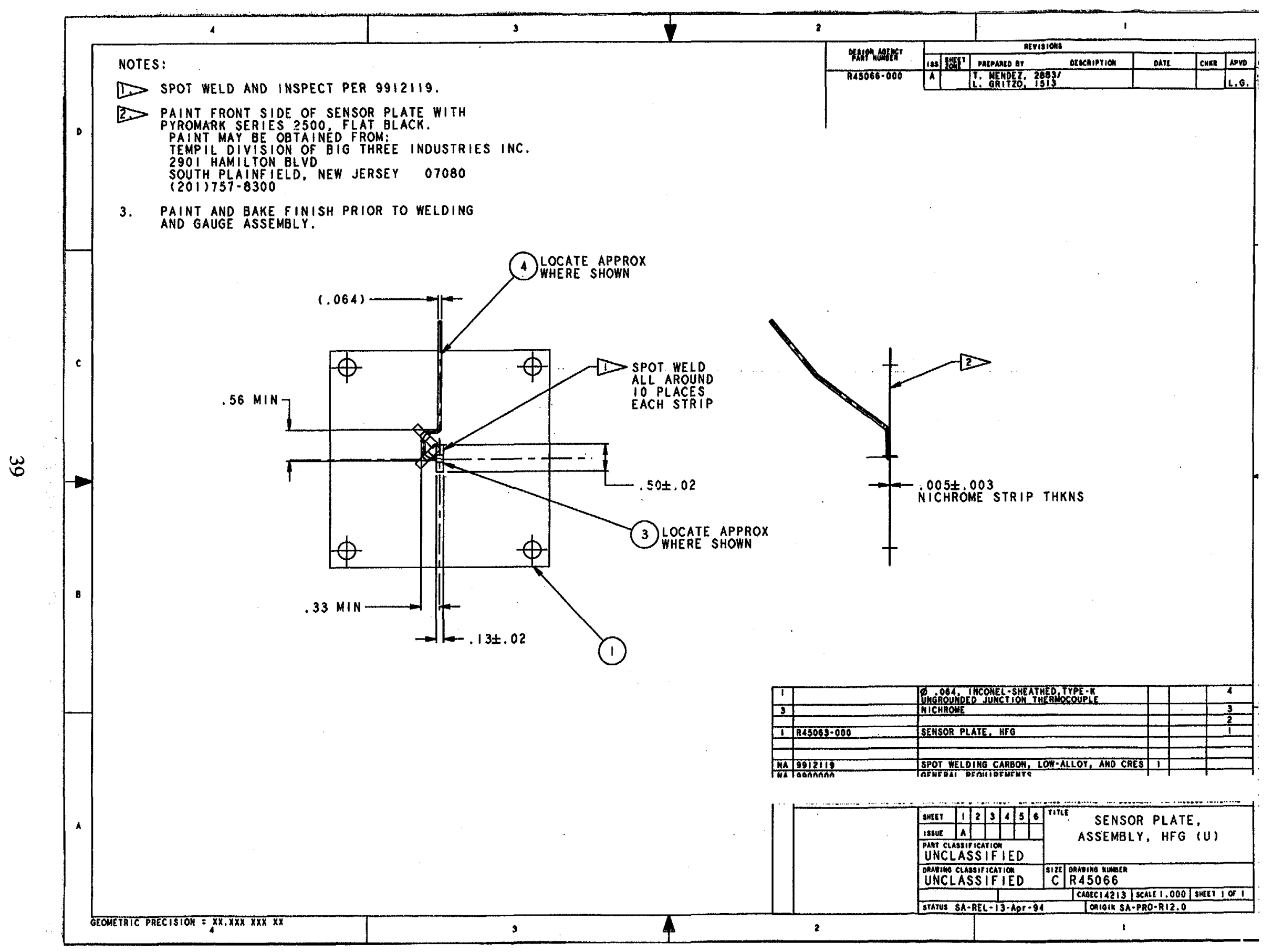




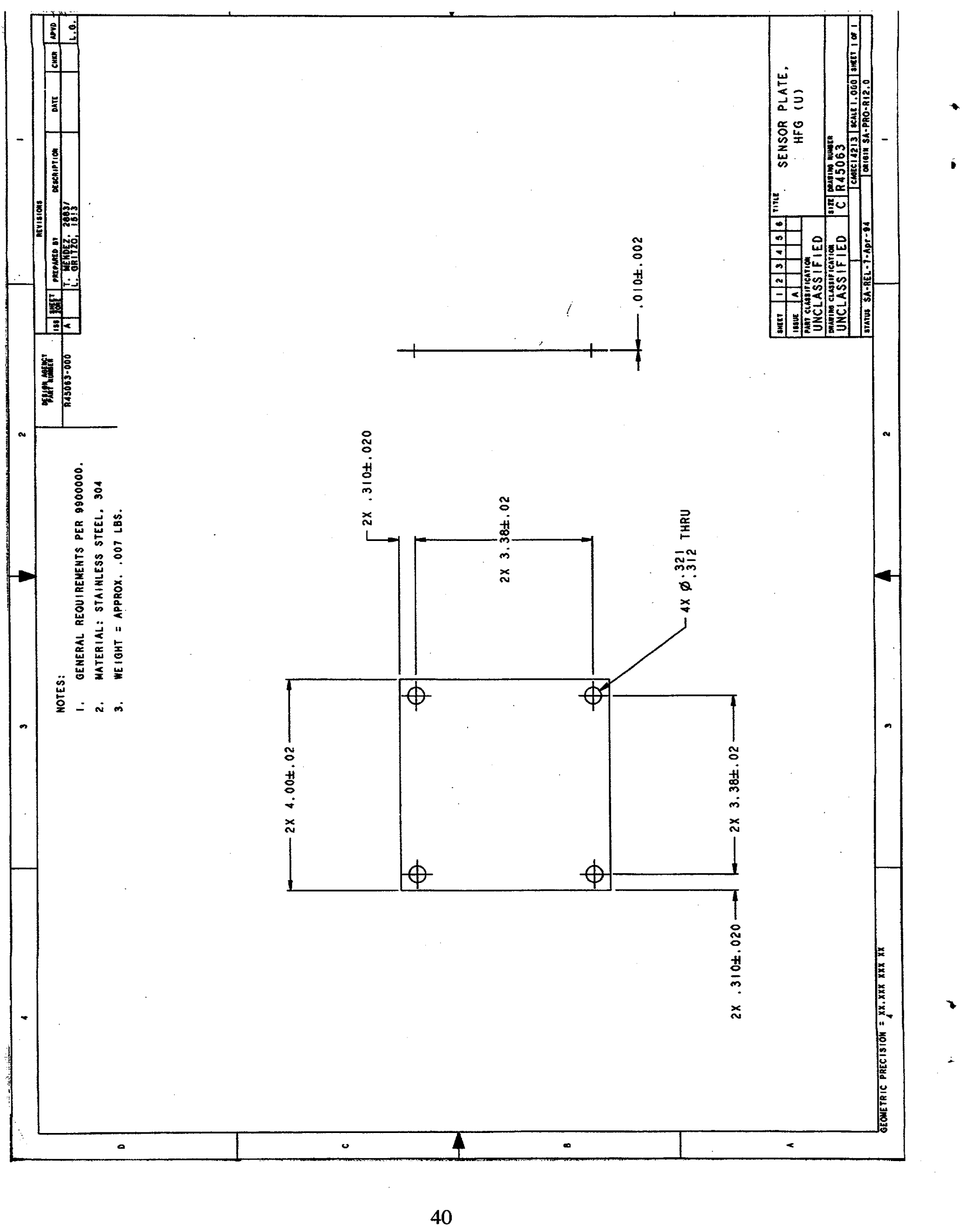




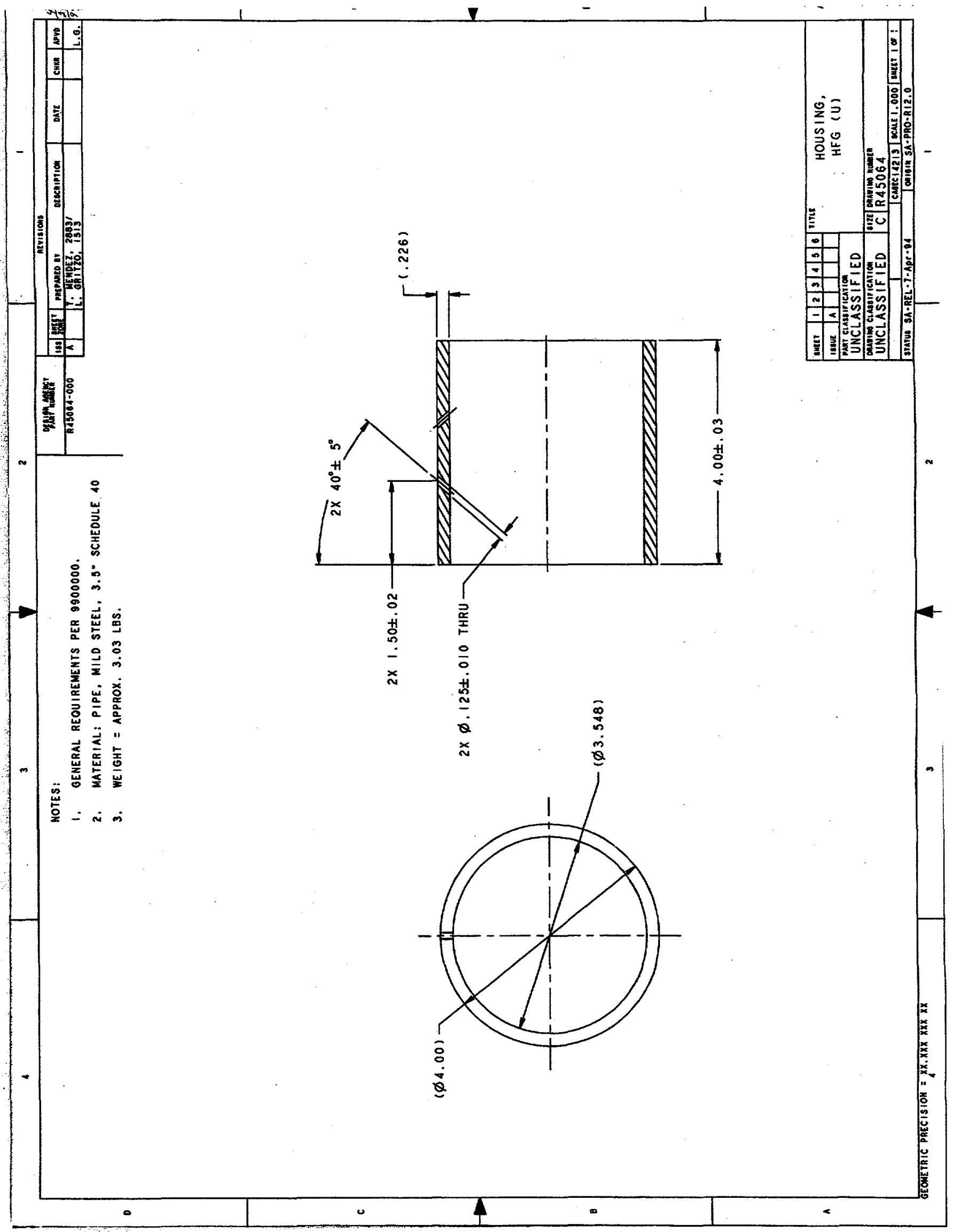




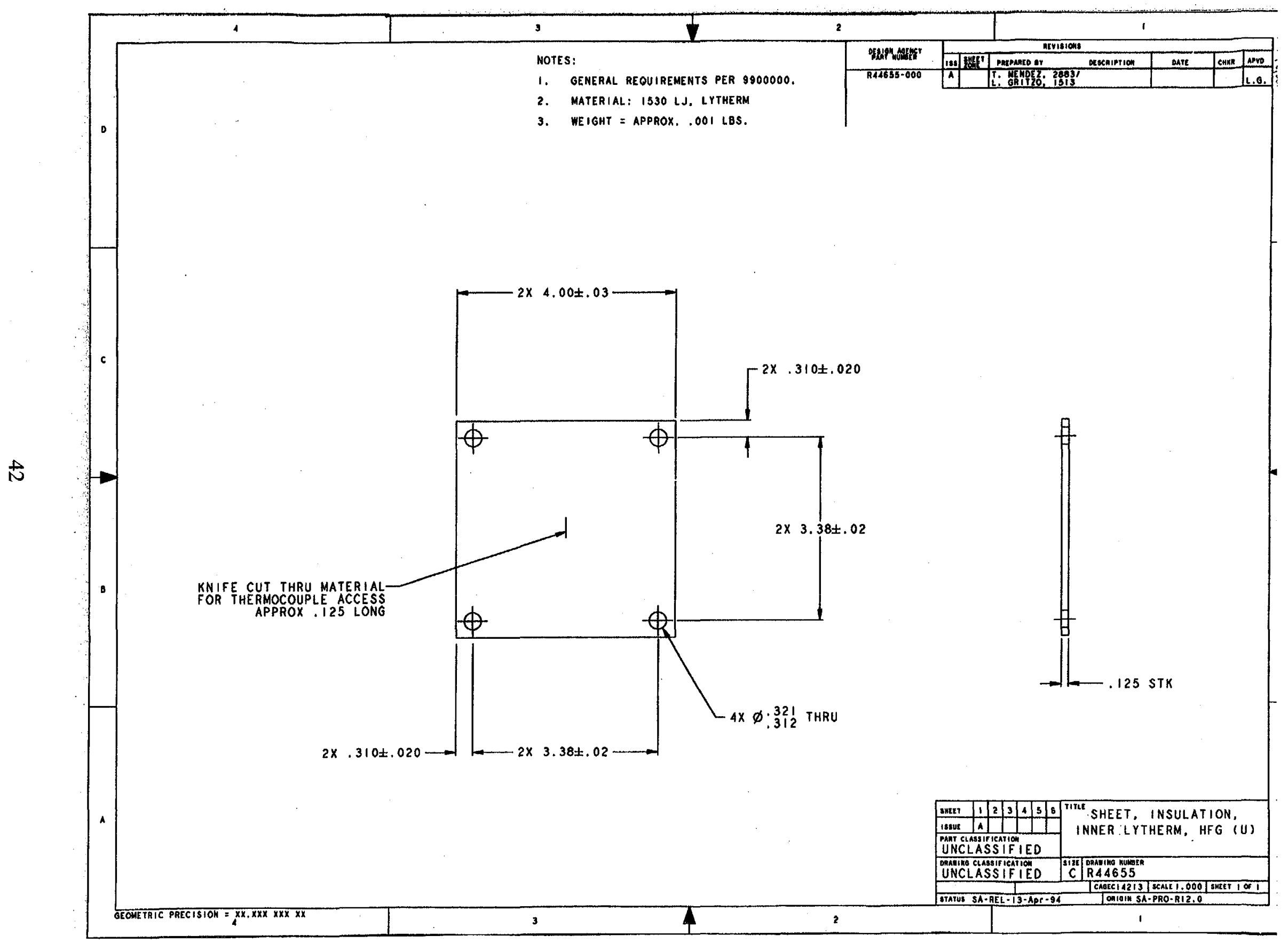




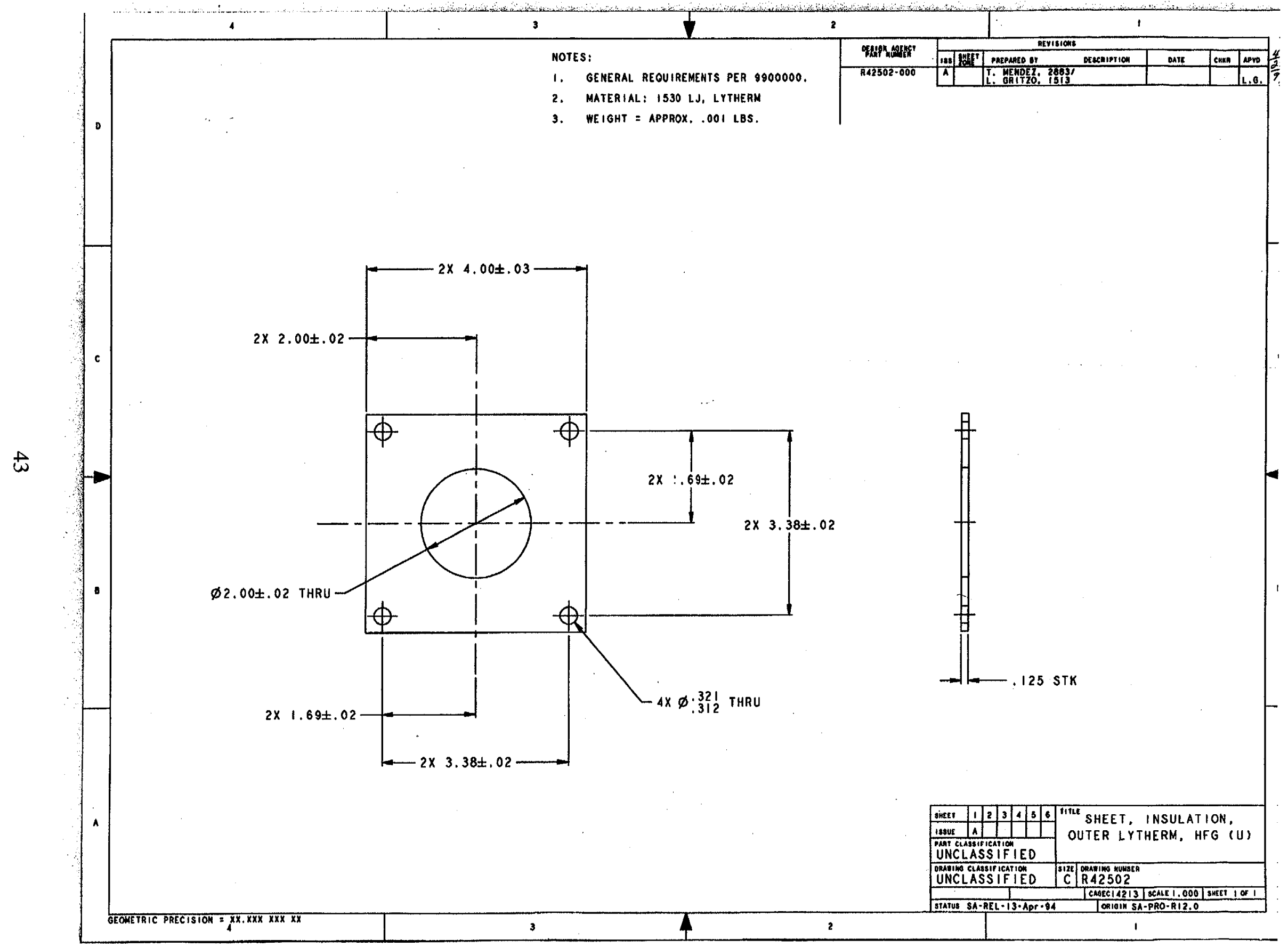




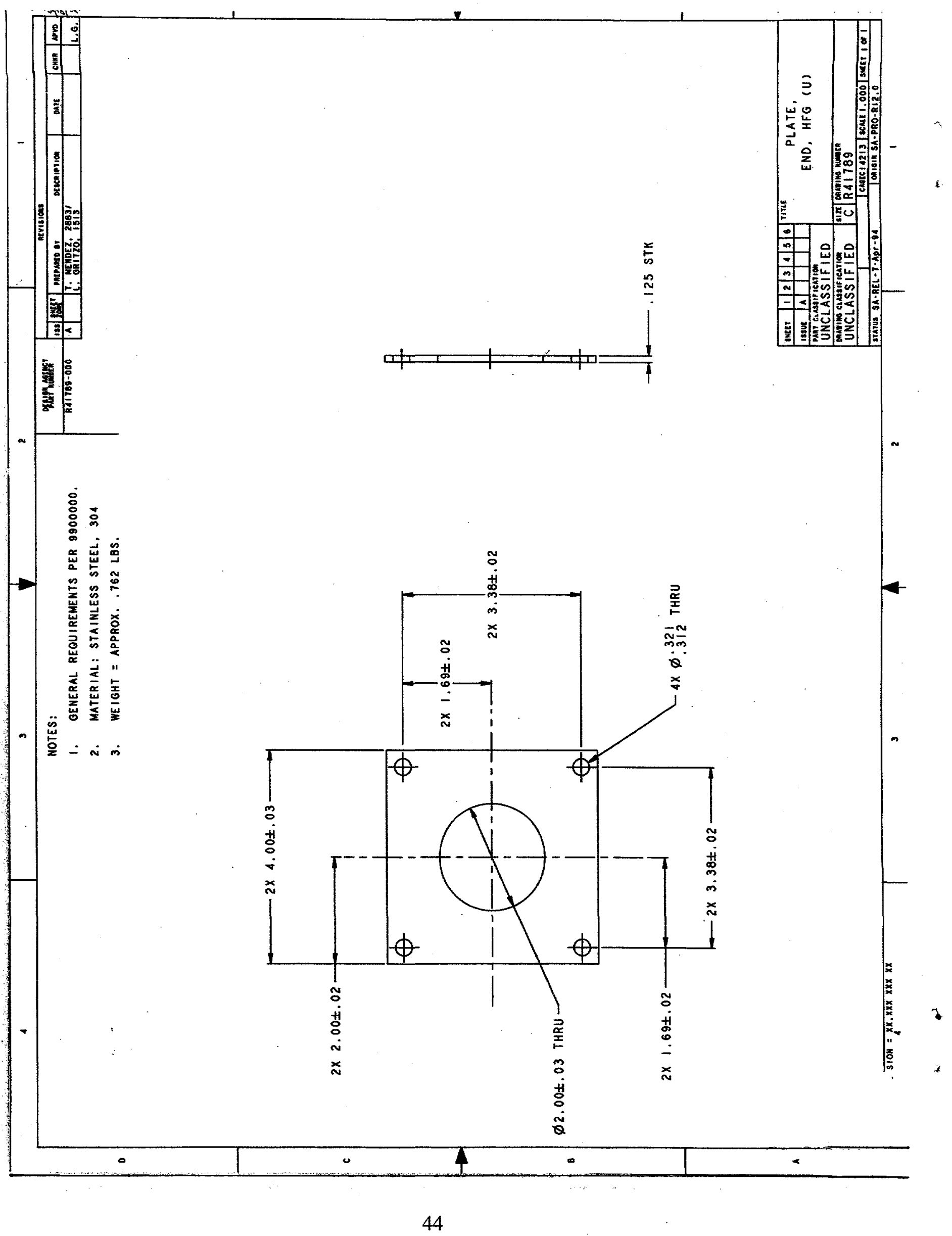




\section{DISTRIBUTION}

Defense Threat Reduction Agency (4)

ATTN: Lt. Col. John A. Dorian Maj. Jeffrey Blank Lt. Cmdr. Michael McLean Maj. David A. LaGraffe

6801 Telegraph Road

Alexandria, VA 22310-3398

Steve Fogarty

ARES Corporation

851 University Boulevard SE, Suite 100

Albuquerque, New Mexico 87106

Ahti Suo-Anttila

6000 Uptown Blvd, Suite 300

Albuquerque, NM 87110

Telephone: (505) 872-1089

Art Barondes

RDA Logicon

6940 South Kings Highway, Suite 202

Alexandria, VA 22310-3344 $\begin{array}{ll}\text { MS0736 } & \text { T. E. Blejwas, } 6400 \\ \text { MS1139 } & \text { K. O. Reil, 6423 } \\ \text { MS1139 } & \text { J. H. Bentz, 6423 } \\ \text { MS1139 } & \text { T. E. Blanchat, 6423 (10) } \\ \text { MS1139 } & \text { L. L. Humphries, } 6423 \\ \text { MS0828 } & \text { T Y Chu, } 9100 \\ \text { MS0828 } & \text { T. C. Bickel, } 9101 \\ \text { MS0834 } & \text { A. C. Ratzel, } 9112 \\ \text { MS0834 } & \text { S. P. Kearny, } 9112 \\ \text { MS0836 } & \text { E. S. Hertel, 9116 } \\ \text { MS0553 } & \text { W. Gill, } 9116(3) \\ \text { MS0836 } & \text { C. E. Hickox, 9116 (3) } \\ \text { MS0836 } & \text { L. A. Gritzo, } 9116 \\ \text { MS0836 } & \text { V. F. Nicolette, 9116 } \\ \text { MS0836 } & \text { S. R. Tiezsen, } 9116 \\ \text { MS0836 } & \text { J. M. Williams, } 9116 \\ \text { MS0828 } & \text { J. L. Moya, 9132 } \\ \text { MS0828 } & \text { M. Pilch, } 9133 \\ \text { MS0828 } & \text { B. F. Blackwell, 9133 } \\ \text { MS0828 } & \text { A. R. Lopez, } 9133 \\ \text { MS0555 } & \text { J. T. Nakos, } 9134 \\ \text { MS0555 } & \text { N. R. Keltner, } 9134 \\ \text { MS9018 } & \text { Central Technical Files (8940-2) } \\ \text { MS0899 } & \text { Technical Library, 9616 (2) } \\ \text { MS0612 } & \text { Review and Approval Desk, 9612 } \\ & \text { For DOE/OSTI } \\ \text { MS0161 } & \text { Patent and Licensing Office, 11500 }\end{array}$ 